Indexed by

\title{
Scopus MANUFACTURING SYSTEM WITH DELAYED DIFFERENTIATION, OUTSOURCING, EXPEDITED RATE, AND REWORK STRATEGIES
}

\section{Yuan-Shyi Peter Chiu}

Chaoyang University of Technology, Department of Industrial Engineering \& Management, Wufeng, Taiwan

\section{Chih-Yun Ke}

Chaoyang University of Technology, Department of Industri-al Engineering \& Management, Wufeng, Taiwan

\author{
Victoria Chiu \\ State University of New York \\ at Oswego, Department of \\ Accounting, Finance and Law, \\ Oswego, USA
}

\section{Ming-Hon Hwang}

Chaoyang University of Technology, Department of Marketing \& Logistics Management, Wufeng, Taiwan

Key words: optimization, multi-item manufacturing, delayed differentiation, rework, expedited rate, outsourcing doi:10.5937/jaes0-30139

Cite article:

Chiu Peter Y.S., Ke C.Y., Chiu V., Hwang M.H. (2021) OPTIMIZING A MULTIPRODUCT MANUFACTURING SYSTEM WITH DELAYED DIFFERENTIATION, OUTSOURCING, EXPEDITED RATE, AND REWORK STRATEGIES, Journal of Applied Engineering Science, 19(4), 1020 - 1034 , DOI:10.5937/ jaes0-30139

Online aceess of full paper is available at: www.engineeringscience.rs/browse-issues 


\title{
OPTIMIZING A MULTIPRODUCT MANUFACTURING SYSTEM WITH DELAYED DIFFERENTIATION, OUTSOURCING, EXPEDITED RATE, AND REWORK STRATEGIES
}

\author{
Yuan-Shyi Peter Chiu', Chih-Yun Ke', Victoria Chiu', Ming-Hon Hwang ${ }^{3 *}$ \\ ${ }^{1}$ Chaoyang University of Technology, Department of Industrial Engineering \& Management, Wufeng, Taiwan \\ ${ }^{2}$ State University of New York at Oswego, Department of Accounting, Finance and Law, Oswego, USA \\ ${ }^{3}$ Chaoyang University of Technology, Department of Marketing \& Logistics Management, Wufeng, Taiwan
}

This study examines the effect of delayed differentiation, outsourcing, expedited fabrication rate, and rework strategies on optimal cycle-time decisions for a multi-item manufacturing system. Today's manufacturing firms must simultaneously deal with externally increasing client multi-item requirements with rapid lead-time and high-quality products and internally on a limited capacity. This study is aimed at assisting manufacturers in meeting client needs in conditions of restricted-capacity and minimum total operating expenses, and adopts a delayed differentiation twostage multiproduct manufacturing scheme to manage the end products' commonality. The first stage produces all required common components, and the second stage fabricates individual finished goods. In both stages, we adopt the reworking of the inevitable nonconforming items produced to assure product quality. Furthermore, we implemented partial outsourcing of common parts' batch and expedited the manufacturing rate of finished products to effectively reduce the uptimes in both stages. We explicitly developed a model to describe the characteristics of the problem. Mathematical analyses with optimization proved the cost function's convexity and determined the cost-minimization rotation cycle policy. Finally, we numerically validated our model's and results' applicability and capability with a simulated example. Apart from creating a useful decision model, this study makes another important contribution to the existing literature in that its revelation of collective/individual effect of the manufacturing-relevant methods on the problem's best-operating cycle policy and crucial performance indices helps manufacturers have better control over their operations and make effective and efficient managerial decisions.

Key words: optimization, multi-item manufacturing, delayed differentiation, rework, expedited rate, outsourcing

\section{INTRODUCTION}

This study examines a two-stage delayed-differentiation multiproduct fabrication system featuring commonality, outsourcing, expedited rate, and rework. It aims to derive the cost-minimized rotation cycle length with reduced-uptime to help manufacturers meet clients' timely multi-item needs in conditions of limited-capacity and minimum total operating expenses. The existing literature indicated that the delayed-differentiation scheme allowed production managers to manage end products' commonality and enabled manufacturing firms to gain competitive advantages in cost savings and order response time reduction. The relevant literature is surveyed below.

\section{Survey of previous research}

The past studies relating to commonality and postponement strategy are surveyed below: Silver and Minner [1] derived the optimal replenishing decision for a fast-food operating environment considering a partial postponement strategy. The researchers developed replenishment solution procedures for various end stocks with random demand and partial delayed-differentiation plans of finite periods. They further provided numerical examples to validate their results and offered numerous managerial insights. Kuthambalayan et al. [2] studied profit-maxi- mized operational and marketing decisions of an assemble-to-order system featuring various product demands, short order lead times, and commonality in semi-finished components. The researchers developed an integrated two-stage stochastic model capturing trade-offs relating to stochastic needs with guaranteed lead times, semi-finished stocks, and outsourcing expenses to examine the marketing decisions on products' lead-time and prices. Prataviera et al. [3] explored the postponement discipline in a global downstream supply-chain environment. The researchers first structurally reviewed and expanded the relevant prior works and then offered several conceptual guidelines on implementing the postponement strategies. The researchers applied their proposed framework to twenty-eight cases from the literature to verify and demonstrate its applicability. Recent works [4-7] also examined the effect of various postponement strategies on the operations planning and management of multi-item manufacturing systems.

This study considers the reworking of inevitable defective stocks produced in the proposed multi-item manufacturing system. Product quality is essential to meet client satisfaction and allow manufacturing firms to stay competitive. No doubt, it has drawn extensive atten- 
tion during the past decades. Lee et al. [8] developed a cost-effective approach to determine process tolerances that minimized the relevant rework and scrap expenses. The researchers compared their approach's result with other methods to demonstrate its effective performance in designing the process tolerances. Pasandideh et al. [9] studied a multiproduct economic production quantity problem with limited storage space and reworking of nonconforming products. A genetic algorithm was utilized to resolve their nonlinear integer-programming model. Nobil et al. [10] studied a multiproduct single-machine fabrication system featuring setup times, scrap, rework, and shortage to determine the cost-minimized fabrication time and shortages. The researchers numerically validated their model, algorithm, and results. Recent works [11-14] also explored the influence of various rework/quality assurance strategies on different manufacturing-inventory systems.

To cope with the client increasing trend on short order lead-time, production planners regularly use effective strategies, such as outsourcing and expedited manufacturing rate, to reduce their fabrication uptime. Sung and Han [15] derived the optimal feeding buffer's storage capacity for a periodic review order-up-to-R stock replenishing system that minimized the expected stock holding and shortage costs. Lehtinen [16] discussed and evaluated the past decade's subcontracting systems of the Finnish manufacturers. The researchers found that the precise subcontracting shifts toward the commitment- based vendor-client long-term relationships among the producers. Also, managing inbound logistics and cooperating with other firms were crucial to the successful subcontracting tasks. Momme and Hvolby [17] proposed a four-phase outsourcing model to explore essential workflow and cross-function in the manufacturing outsourcing process. The model attempted to serve as a marketing tool externally and a practical outline and management tool internally to facilitate strategic planning in industrial and academic applications. Soni and Patel [18] proposed an algorithm to determine the profit-maximized retail price, replenishing cycle, and shipment frequency policies for an inventory system featuring variable fabrication rate, price-dependent demands, and dual trade-credit levels. The researchers assumed a random defective rate, and the full trade credit was granted from the supplier to the retailer, and a partial trade credit was offered from the retailer to its client. Akkermans et al. [19] examined the key performance indicators (KPIs) of contracting services in a design science client-vendor collaborative environment. The researchers first discussed/ evaluated KPIs of a real case of outsourcing information technology services of a telecommunication vendor and then extended to two different settings to demonstrate their evaluation procedures at both client and vendor sides. Recent works [20-23] also explored the impact of different aspects of adjusted fabrication rate and subcontracting on planning, operations, and management of diverse manufacturing and supply-chain systems. Since few past works have developed a precise model to derive the optimal replenishing policy and explicitly disclose collective/individual impact of postponement, rework, and dual uptime-reduced strategies on the problem's operating cycle policy and crucial performance indices, we aim to serve this purpose and help manufacturers have better control over their operations and facilitate their effective/efficient decision-making.

\section{MATERIALS AND METHODS}

This study optimizes a multi-item manufacturing system with delayed differentiation, outsourcing, expedited rate, and rework strategies. The following are the definition of all relevant notation:

\section{Problem description}

This study determines the optimal cycle time for a multi-item manufacturing system incorporating delayed differentiation, partial outsourcing common parts, the expedited rate for end products, and the rework of nonconforming products. The following Nomenclature helps explain our explicit model that carefully depicts our studied model.

This study determines the optimal cycle time for a multiitem manufacturing system incorporating delayed differentiation, partial outsourcing common parts, the expedited rate for end products, and the rework of defective items. We build a precise mathematical model to determine the optimal rotation batch cycle time for a multiitem manufacturing problem. Assume the common part exists in $L$ different customer products; each has annual requirements $\lambda_{i}$ (where $i=1,2, \ldots, L$ ). To simplify their production processes and reduce total uptimes, we use a two-stage delayed differentiation fabrication scheme. Stage one produces all necessary common parts, and stage two manufactures finished products. Figure 1 illustrates the proposed system's stock status featuring partial outsourcing of common parts in stage one, the expedited rate for finished products in stage two, and the reworking of inevitable defective items in both phases. We assume common part's completion rate $y$ is constant, and both the common part and end product's fabrication rates $P_{1,0}$ and $P_{1}$, depend on $\gamma$. For example, if $Y=0.5$, then both $P_{1,0}$ and $P_{1, i}$ are twice as much as their regular rates in a single-stage system.

This study appoints an external source to satisfy $a \pi_{0}$ portion of common part's batch and implements an expedited rate for fabricating $L$ different end products to shorten cycle length. These strategies affect the following parameters concerning cost, and manufacturing and reworking rates (refer to the definition of variables in Nomenclature):

$$
\begin{aligned}
& C_{\pi 0}=\left(1+\beta_{2,0}\right) C_{0} \\
& K_{\pi 0}=\left(1+\beta_{1,0}\right) K_{0} \\
& P_{T 1, i}=\left(1+\alpha_{1, i}\right) P_{1, i}
\end{aligned}
$$




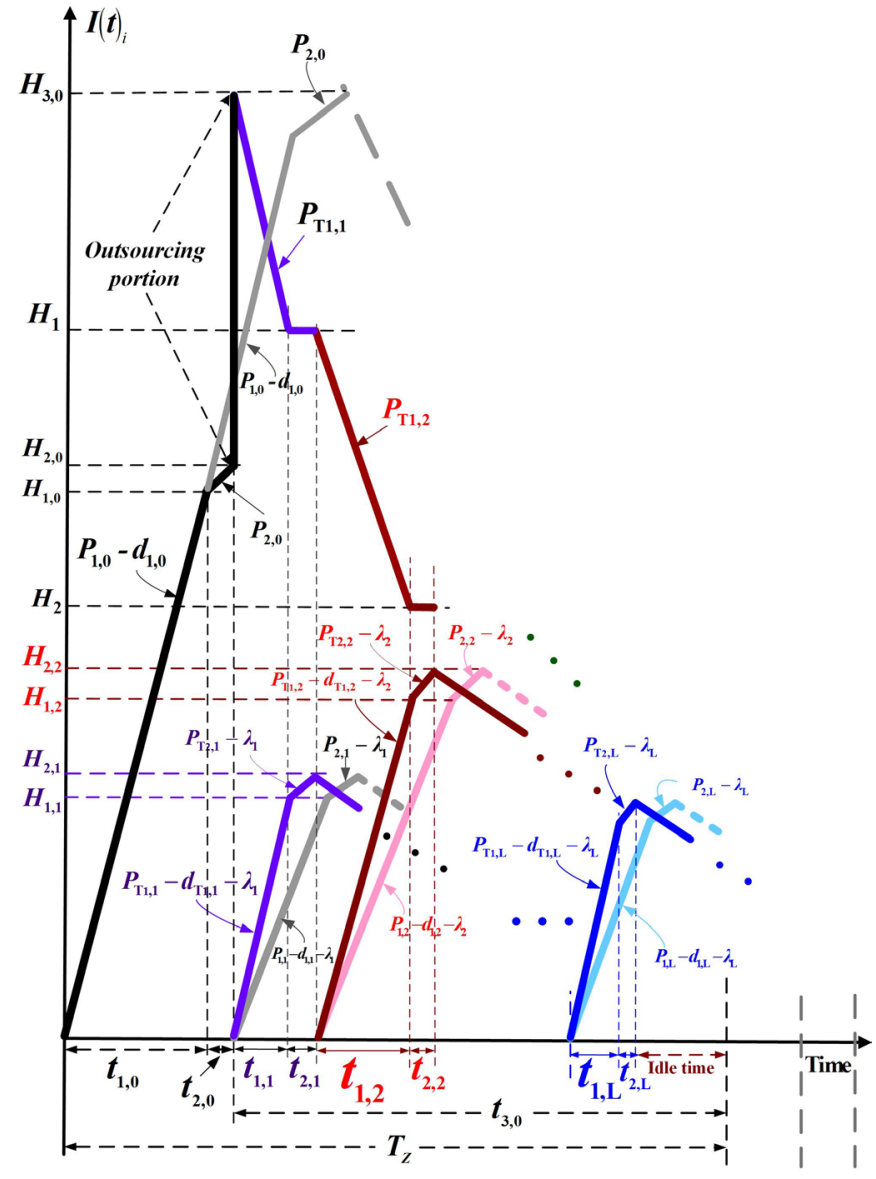

Figure 1: The stock status in the studied multi-item manufacturing system with the strategies of delayed-differentiation, outsourcing, rework, and expedited rate compared to the same system without neither strategies

$P_{T 2, i}=\left(1+\alpha_{1, i}\right) P_{2, i}$

$C_{T, i}=\left(1+\alpha_{3, i}\right) C_{i}$

$C_{T R, i}=\left(1+\alpha_{3, i}\right) C_{R, i}$

$K_{T, i}=\left(1+\alpha_{2, i}\right) K_{i}$

This study assumes that both manufacturing stages are not perfect. Random nonconforming rates $x_{0}$ and $x_{1}$ (where $i=1,2, \ldots, L$ ) exist. These items are identified and repaired via a rework process. Figure 1 indicates that the common part's stock level piles up to $\mathrm{H}_{1,0}$ when $\mathrm{t}_{1,0}$ ends, and it continues to accumulate to $\mathrm{H}_{2,0}$ when reworking time $t_{2,0}$ completes. Meantime, the external contractor supplies outsourced items and brings the common part's stock level to $H_{30}$ before the beginning of stage two. In stage two, the stock level of end product i piles up to $\mathrm{H}_{1,}$, when the uptime $t 1$, i ends, and it continues to accumulate to $\mathrm{H}_{2, i}$ when reworking time $t_{2, i}$ completes. Then, the stock level of end item i depletes under a continuous issuing plan (see Fig. 1).

Figure 2 illustrates the nonconforming stock's status in the studied multi-item manufacturing system. It shows the nonconforming common part's level accumulates to $\left(d_{1,0}\right.$

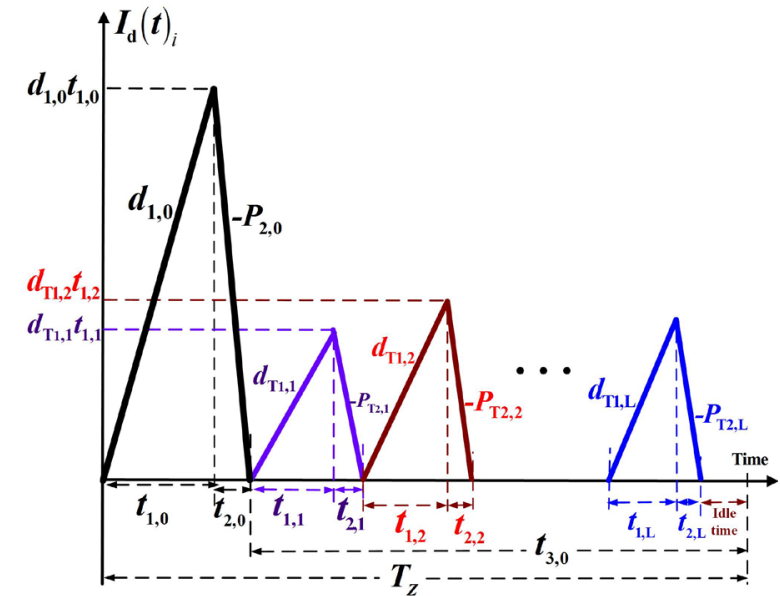

Figure 2: The nonconforming stock's status in the studied multi-item manufacturing system

$t_{1,0}$ ) when $t_{1,0}$ ends, and it gradually drops to zero in $t_{2,0}$. $\ln$ stage two, similar situations occur for the nonconforming end products. Since this study does not allow shortages, hence the following equations must hold: for stage one, $\left(P_{1,0}-d_{1,0}\right)>0$ and for stage two, $\left(P T_{1, i}-d T_{1, i}-\lambda_{i}\right)>0$.

\section{Problem formulations}

To manufacture $L$ different products in stage two, the needed common parts for each product $i$ are gradually depleted (see Figure 1). Hence, the common parts start to decline $Q_{i}$ quantity from $H_{3,0}$ to $H_{i}$, when the uptime of each product i ends. Formulas (8) to (10) show common parts' status in stage 2, and Figure 3 depicts the common part's status during its fabrication process of each product $i$.

$H_{1}=H_{3,0}-Q_{1}$

$H_{i}=H_{(i-1)}-Q_{i}$, for $i=2,3, \ldots, L$

$H_{L}=H_{(L-1)}-Q_{L}=0$

We can straightforwardly observe the following formulas from the problem description along with Figures 1 to 3 :

$T_{z}=t_{1, i}+t_{2, i}+t_{3, i}$ where $i=0,1,2, \ldots, L$

$Q_{i}=\lambda_{i} T_{z}$

$t_{1, i}=\frac{Q_{i}}{P_{T 1, i}}$

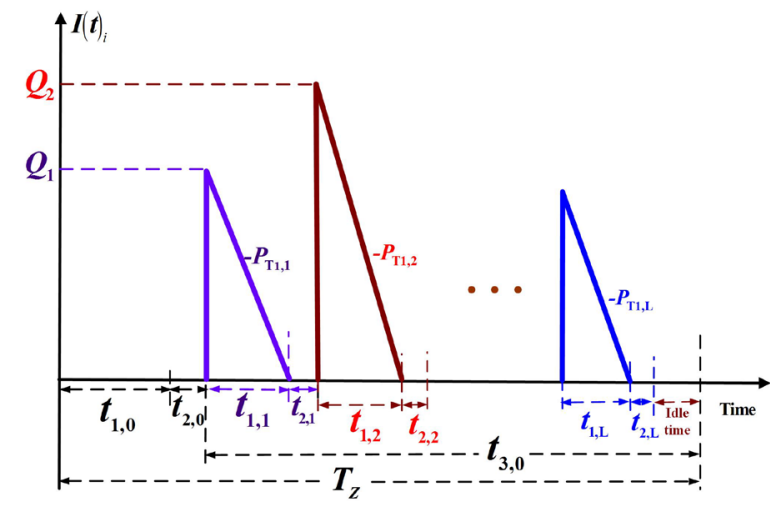

Figure 3: Common part's status in stage-2 of the multi-item manufacturing system 
$H_{1, i}=\left(P_{T 1, i}-d_{T 1, i}-\Lambda_{i}\right) t_{1, i}$

$H_{2, i}=H_{1, i}+\left(P_{T 2, i}-\lambda_{i}\right) t_{2, i}$

$t_{2, i}=\frac{H_{2, i}-H_{1, i}}{P_{T 2, i}-\lambda_{i}}$

$t_{3, i}=\frac{H_{2, i}}{\lambda_{i}}$

To satisfy the total batch sizes of item $i$ (where $i=1,2, \ldots$, $L)$, the needed common parts are given as follows:

$H_{3,0}=\sum_{i=1}^{L} Q_{i}=\sum_{i=1}^{L} \lambda_{i} T_{Z}$

$\lambda_{0}=\frac{\sum_{i=1}^{L} Q_{i}}{T_{Z}}$

$Q_{0}=H_{2,0}=\left(1-\Pi_{0}\right) H_{3,0}=\left(1-\Pi_{0}\right)\left(\sum_{i=1}^{L} Q_{i}\right)$

$t_{1,0}=\frac{Q_{0}}{P_{1,0}}$

$H_{2,0}=H_{1,0}+P_{2,0} t_{2,0}$

$H_{1,0}=\left(P_{1,0}-d_{1,0}\right) t_{1,0}$

$t_{2,0}=\frac{Q_{0} x_{0}}{P_{2,0}}=\frac{H_{2,0}-H_{1,0}}{P_{2,0}}$

\section{The cost analysis and optimization process}

The total cost per replenishment cycle $T C\left(T_{z}\right)$ comprises expenses incurred in both stages as follows: (I) stage one's variable and setup costs for outsourcing and in-house production, and the stockholding and rework costs; (II) stage two's sum of variable, setup, stock holding and rework costs for manufacturing $L$ products. Therefore, $T C\left(T_{z}\right)$ is as follows:

$$
\begin{aligned}
T C\left(T_{Z}\right) & =\left[\Pi_{0}\left(\sum_{i=1}^{L} Q_{i}\right)\right] C_{\pi 0}+K_{\pi 0}+C_{0} Q_{0}+K_{0}+Q_{0} x_{0} C_{R, 0}+h_{2,0}\left(\frac{d_{1,0} t_{1,0}}{2}\right)\left(t_{2,0}\right) \\
& +h_{1,0}\left[\frac{H_{1,0} t_{1,0}}{2}+\frac{d_{1,0} t_{1,0}}{2}\left(t_{1,0}\right)+\frac{H_{2,0}+H_{1,0}}{2}\left(t_{2,0}\right)+\sum_{i=1}^{L}\left[\frac{Q_{i}}{2}\left(t_{1, i}\right)+H_{i}\left(t_{1, i}+t_{2, i}\right)\right]\right] \\
& +\sum_{i=1}^{L}\left\{\begin{array}{l}
Q_{i} C_{T, i}+K_{T, i}+Q_{i} x_{i} C_{T R, i}+h_{2, i}\left(\frac{d_{T 1, i} t_{1, i}}{2}\right)\left(t_{2, i}\right) \\
\left.+h_{1, i}\left[\frac{H_{1, i} t_{1, i}}{2}+\frac{d_{T 1, i} t_{1, i}}{2}\left(t_{1, i}\right)+\frac{H_{2, i}+H_{1, i}}{2}\left(t_{2, i}\right)+\frac{H_{2, i}}{2}\left(t_{3, i}\right)\right]\right\}
\end{array}\right.
\end{aligned}
$$

Apply the expected values $E\left[X_{i}\right]$ (for $i=0,1,2, \ldots, L$ ) to cope with random nonconforming rates, replace Eqs. (1) to (24) in $T C\left(T_{z}\right)$, and with additional derivation efforts, we derive the following expected cost per unit time $E\left[\operatorname{TCU}\left(T_{z}\right)\right]$ (see Appendix A):

$\begin{aligned} E\left[T C U\left(T_{z}\right)\right]= & \left\{\begin{array}{l}\frac{\left(1+\beta_{1,0}\right) K_{0}}{T_{z}}+\left(1+\beta_{2,0}\right) C_{0} \Pi_{0} \lambda_{0}+C_{0}\left(1-\Pi_{0}\right) \lambda_{0}+\frac{h_{2,0} E\left[x_{0}\right]^{2} E_{0 \pi}}{2 P_{2,0}} T_{z}+\frac{h_{1,0} E_{0 \pi} E_{0 P}}{2} T_{z} \\ +\frac{K_{0}}{T_{z}}+C_{R, 0} E\left[x_{0}\right]\left(1-\Pi_{0}\right) \lambda_{0}+h_{1,0} \sum_{i=1}^{L}\left\{\frac{\lambda_{i}^{2} T_{z}}{2\left(1+\alpha_{1, i}\right) P_{1, i}}+\left(\sum_{i=1}^{L}\left(\lambda_{i} T_{z}\right)-\sum_{j=1}^{i}\left(\lambda_{j} T_{z}\right)\right) \lambda_{i} E_{2 i}\right\}\end{array}\right\} \\ & +\sum_{i=1}^{L}\left\{\left(1+\alpha_{3, i}\right) C_{i} \lambda_{i}+\frac{\left[\left(1+\alpha_{2, i}\right) K_{i}\right]}{T_{z}}+\left(1+\alpha_{3, i}\right) C_{R, i} E\left[x_{i}\right] \lambda_{i}+h_{2, i} E_{1 i} T_{z}+h_{1, i}\left[\frac{\lambda_{i}^{2} E_{3 i}}{2}\right] T_{z}\right.\end{aligned}$
To seek the optimal cycle time, we apply the first- and second-derivatives to $E\left[T C U\left(T_{z}\right)\right]$ as follows:

$\frac{d E\left[T C U\left(T_{z}\right)\right]}{d\left(T_{z}\right)}=\left\{\begin{array}{l}-\frac{\left(1+\beta_{1,0}\right) K_{0}}{T_{z}^{2}}-\frac{K_{0}}{T_{z}^{2}}+\frac{h_{2,0} E\left[x_{0}\right]^{2} E_{0 \pi}}{2 P_{2,0}}+\frac{h_{1,0} E_{0 \pi} E_{0 P}}{2} \\ +h_{1,0}^{L} \sum_{i=1}^{L}\left\{\frac{\lambda_{i}^{2}}{2\left(1+\alpha_{1, i}\right) P_{1, i}}+\left(\sum_{i=1}^{L}\left(\lambda_{i}\right)-\sum_{j=1}^{i}\left(\lambda_{j}\right)\right) \lambda_{i} E_{2 i}\right\}\end{array}\right\}+\sum_{i=1}^{L}\left\{-\frac{\left(1+\alpha_{2, i}\right) K_{i}}{T_{z}^{2}}+h_{2, i} E_{1 i}+h_{1, i} \frac{\lambda_{i}^{2} E_{3 i}}{2}\right\}$

$\frac{d^{2} E\left[\operatorname{TCU}\left(T_{z}\right)\right]}{d\left(T_{z}\right)^{2}}=\frac{2\left[\left(1+\beta_{1,0}\right) K_{0}\right]}{T_{z}^{3}}+\frac{2 K_{0}}{T_{z}^{3}}+\sum_{i=1}^{L}\left\{\frac{2\left[\left(1+\alpha_{2, i}\right) K_{i}\right]}{T_{z}^{3}}\right\}>0$

In Eq. (28), since parameters $\beta_{1,0}, \alpha_{2, i}, T_{Z}, K_{i}$, and $K_{0}$ are all positive; thus, $E\left[\operatorname{TCU}\left(T_{z}\right)\right]$ is convex. Then, let the first derivative equal to zero (i.e., Eq. $(27)=0$ ), we find the optimal $T_{Z}$ *

$$
T_{z}^{*}=\sqrt{\frac{\left(2+\beta_{1,0}\right) K_{0}+\sum_{i=1}^{L}\left[\left(1+\alpha_{2, i}\right) K_{i}\right]}{+\frac{h_{2,0} E\left[x_{0}\right]^{2} E_{0 \pi}}{2 P_{2,0}}+\frac{h_{1,0} E_{0 \pi} E_{0 P}}{2}+h_{1,0} \sum_{i=1}^{L}\left\{\frac{\lambda_{i}^{2}}{2\left(1+\alpha_{1, i}\right) P_{1, i}}+\left(\sum_{i=1}^{L} \lambda_{i}-\sum_{j=1}^{i} \lambda_{j}\right) \lambda_{i} E_{2 i}\right\}}}
$$

where $E_{0 P}, E_{0 \pi}, E_{1 i}, E_{2 i}$, and $E_{3 i}$ are defined in Eqs. (A-2) to $(A-4)$ in Appendix $A$.

\section{Limitation on the total setup times and prerequisite condition}

If the sum of setup times $S_{i}$ is larger than the idle-time of the cycle (refer to Fig. 1), then, extra calculation of $T_{\text {min }}$ is required (Nahmias [24]), and the final optimal cycle length solution to the problem should be the maximum of $\left(T_{Z}^{*}, T_{\min }\right)$.

$$
T_{\min }=\frac{\sum_{i=0}^{L}\left(S_{i}\right)}{1-\left\{\lambda_{0}\left(1-\Pi_{0}\right)\left(\frac{1}{P_{1,0}}+\frac{E\left[x_{0}\right]}{P_{2,0}}\right)+\sum_{i=1}^{L} \lambda_{i}\left[\frac{1}{P_{T 1, i}}+\frac{E\left[x_{i}\right]}{P_{T 2, i}}\right]\right\}}
$$

To ensure that the machine in the proposed study has adequate capacity for manufacturing and reworking common parts and $L$ different products (Nahmias [24]), we must have the following prerequisite condition:

$\left(\left(t_{1,0}+t_{2,0}\right)+\sum_{i=1}^{L}\left(t_{1, i}+t_{2, i}\right)\right)<T_{z}$ or $\left[\left(\frac{Q_{0}}{P_{1,0}}+\frac{Q_{0} E\left[x_{0}\right]}{P_{2,0}}\right)+\sum_{i=1}^{L} Q_{i}\left(\frac{1}{P_{T 1, i}}+\frac{E\left[x_{i}\right]}{P_{T 2, i}}\right)\right]<T_{Z}$

or

$$
\left\{\lambda_{0}\left(1-\Pi_{0}\right)\left(\frac{1}{P_{1,0}}+\frac{E\left[x_{0}\right]}{P_{2,0}}\right)+\sum_{i=1}^{L} \lambda_{i}\left[\frac{1}{P_{T 1, i}}+\frac{E\left[x_{i}\right]}{P_{T 2, i}}\right]\right\}<1
$$

\section{Numerical example with discussion}

A multi-item batch manufacturing system must satisfy the annual demands of five end products that have common part among them. A two-stage scheme featuring delayed differentiation discipline is employed for manufacturing these products. To reduce the cycle time, we outsource a portion of the common parts in stage 1 and use an expedited rate for producing end products in stage 2 . Besides, the reworking of inevitable nonconforming items 
is implemented to retain desirable product quality. Table 1 displays the variables' values assumed in stage one, while Table 2 shows the variables' values assumed in stage two. On the contrary, the variables' values of a relevant single-stage batch manufacturing plan for the same problem are shown in Appendix B (see Table B-1).

Table 1: The variables' values assumed in stage 1

\begin{tabular}{|c|c|c|c|c|c|c|c|}
\hline$\pi_{0}$ & $\mathrm{Y}$ & $\mathrm{x}_{0}$ & $\mathrm{C}_{\mathrm{R}, 0}$ & $\mathrm{P}_{1,0}$ & $\beta_{2.0}$ & $\mathrm{~h}_{1,0}$ & $\mathrm{~h}_{2.0}$ \\
\hline 0.4 & 0.5 & $2.5 \%$ & $\$ 25$ & 120000 & 0.4 & $\$ 8$ & $\$ 8$ \\
\hline$\delta$ & $\mathrm{C}_{0}$ & $\lambda_{0}$ & $\mathrm{~K}_{0}$ & $\beta_{1,0}$ & $\mathrm{P}_{2.0}$ & $\mathrm{i}_{0}$ & \\
\hline 0.5 & $\$ 40$ & 17000 & $\$ 8500$ & -0.7 & 96000 & 0.2 & \\
\hline
\end{tabular}

To find the optimal operating $T_{z}{ }^{*}$ and $E\left[T C U\left(T_{z}^{*}\right)\right]$, we apply formulas (29) and (26) and gain $T_{z}^{*}=0.5944$ and $E\left[\operatorname{TCU}\left(T_{z}^{*}\right)\right]=\$ 2,359,729$. The influence of dual uptime reduction strategies (i.e., outsourcing and expedited rate) on various system parameters is analyzed and shown in Tables C-1 and C-2 (refer to Appendix C).

\section{The collective impact of different features on the problem}

Figure 4 illustrates the investigative outcomes of the collective impact of replenishment cycle length $T_{z}$ and the expedited-rate factor $\alpha_{1, i}$ on $E\left[\operatorname{TCU}\left(T_{z}\right)\right]$. It indicates the convexity of $E\left[T C U\left(T_{z}\right)\right]$ concerning $T_{z}$ for as $T_{z}$ deviates from $T_{Z}{ }^{*}$ (which equals 0.5944), $E\left[T C U\left(T_{z}\right)\right]$ rises in both ways. Also, as the expedited-rate factor $\alpha_{1, \mathrm{i}}$ (in stage two) increases, $E\left[\operatorname{TCU}\left(T_{z}\right)\right]$ upsurges noticeable.

Figure 5 portrays the combined effect of the outsourcing and expedited-rate factors (i.e., $\pi_{0}$ and $\alpha_{1, i}$ ) on the utilization. It reveals that as $\pi_{0}$ increases, the machine utilization declines sharply; as $\alpha_{1, i}$ goes up, the utilization noticeably drops.

Figure 6 depicts the analytical results of the joint influence of $\alpha_{1, \mathrm{i}}$ and $\pi_{0}$ on $E\left[\operatorname{TCU}\left(T_{Z}^{*}\right)\right]$. It specifies that as both $\alpha_{1, \mathrm{i}}$ and $\pi_{0}$ rise, $E\left[\operatorname{TCU}\left(T_{z}^{*}\right)\right]$ surges considerably. Our example indicates that $\alpha_{1, i}$ has more influence than $\pi_{0}$ on $\mathrm{E}\left[T C U\left(T_{Z}^{*}\right)\right]$ increase.

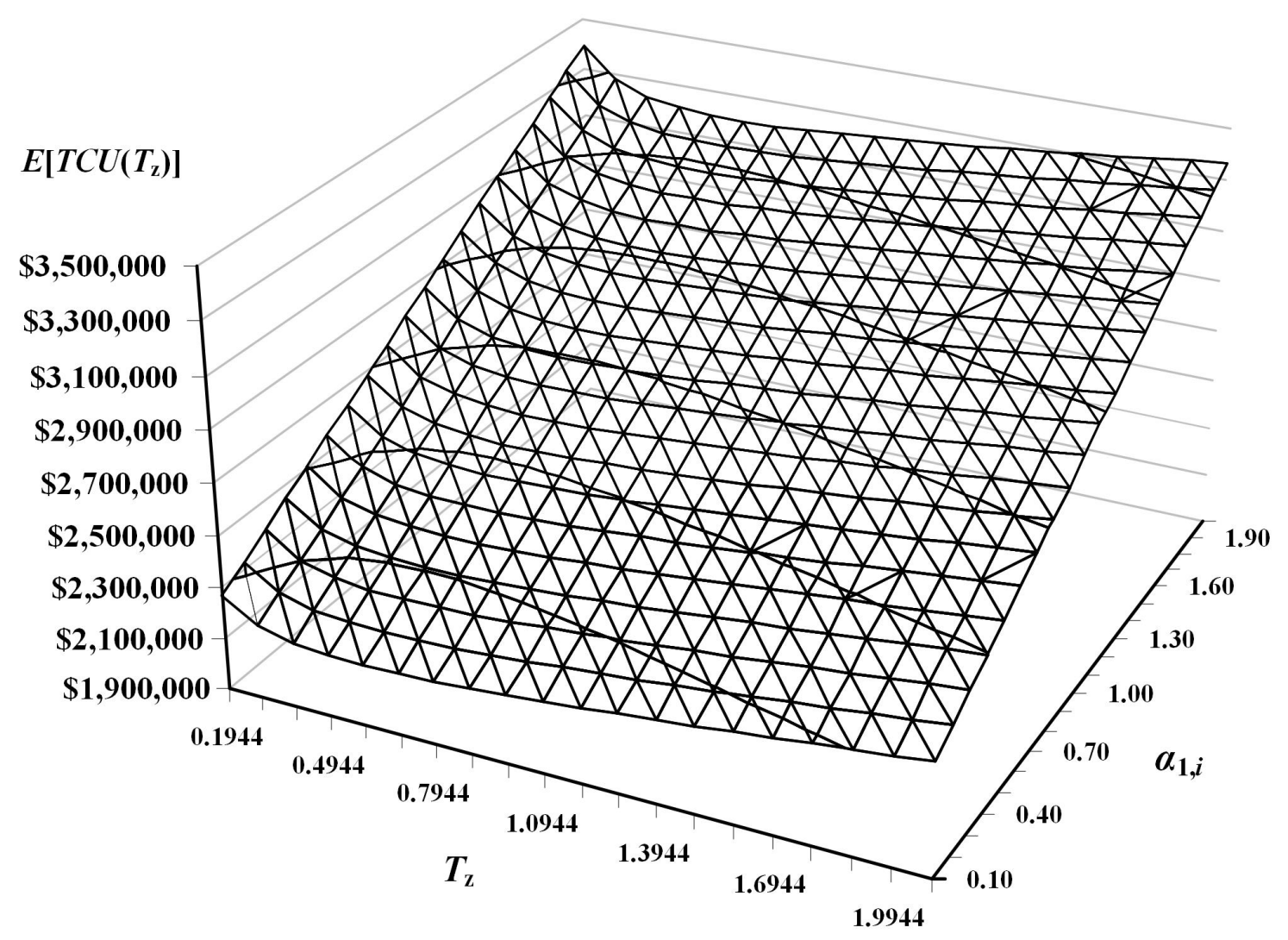

Figure 4: The collective impact of cycle length $T_{Z}$ and expedited-rate factor $\alpha_{1, i}$ on $E\left[T C U\left(T_{z}\right)\right]$

Table 2: The variables' values assumed in stage 2

\begin{tabular}{|c|c|c|c|c|c|c|c|c|c|c|c|c|c|}
\hline Product $\mathrm{i}$ & $\mathrm{\alpha}_{1, \mathrm{j}}$ & $\mathrm{\alpha}_{2, \mathrm{i}}$ & $\mathrm{\alpha}_{3, \mathrm{i}}$ & $\mathrm{xi}$ & $\lambda \mathrm{i}$ & $\mathrm{Ki}$ & $\mathrm{Ci}$ & $\mathrm{P} 1, \mathrm{i}$ & $\mathrm{ii}$ & $\mathrm{h} 1, \mathrm{i}$ & $\mathrm{P}_{2, \mathrm{i}}$ & $\mathrm{C}_{\mathrm{R}, \mathrm{i}}$ & $\mathrm{h}_{2, \mathrm{i}}$ \\
\hline 1 & 0.5 & 0.1 & 0.25 & $2.5 \%$ & 3000 & $\$ 8500$ & $\$ 40$ & 112258 & 0.2 & $\$ 16$ & 89806 & $\$ 25$ & $\$ 16$ \\
\hline 2 & 0.5 & 0.1 & 0.25 & $7.5 \%$ & 3200 & $\$ 9000$ & $\$ 50$ & 116066 & 0.2 & $\$ 18$ & 92852 & $\$ 30$ & $\$ 18$ \\
\hline 3 & 0.5 & 0.1 & 0.25 & $12.5 \%$ & 3400 & $\$ 9500$ & $\$ 60$ & 120000 & 0.2 & $\$ 20$ & 96000 & $\$ 35$ & $\$ 20$ \\
\hline 4 & 0.5 & 0.1 & 0.25 & $17.5 \%$ & 3600 & $\$ 10000$ & $\$ 70$ & 124068 & 0.2 & $\$ 22$ & 99254 & $\$ 40$ & $\$ 22$ \\
\hline 5 & 0.5 & 0.1 & 0.25 & $22.5 \%$ & 3800 & $\$ 10500$ & $\$ 80$ & 128276 & 0.2 & $\$ 24$ & 102621 & $\$ 45$ & $\$ 24$ \\
\hline
\end{tabular}




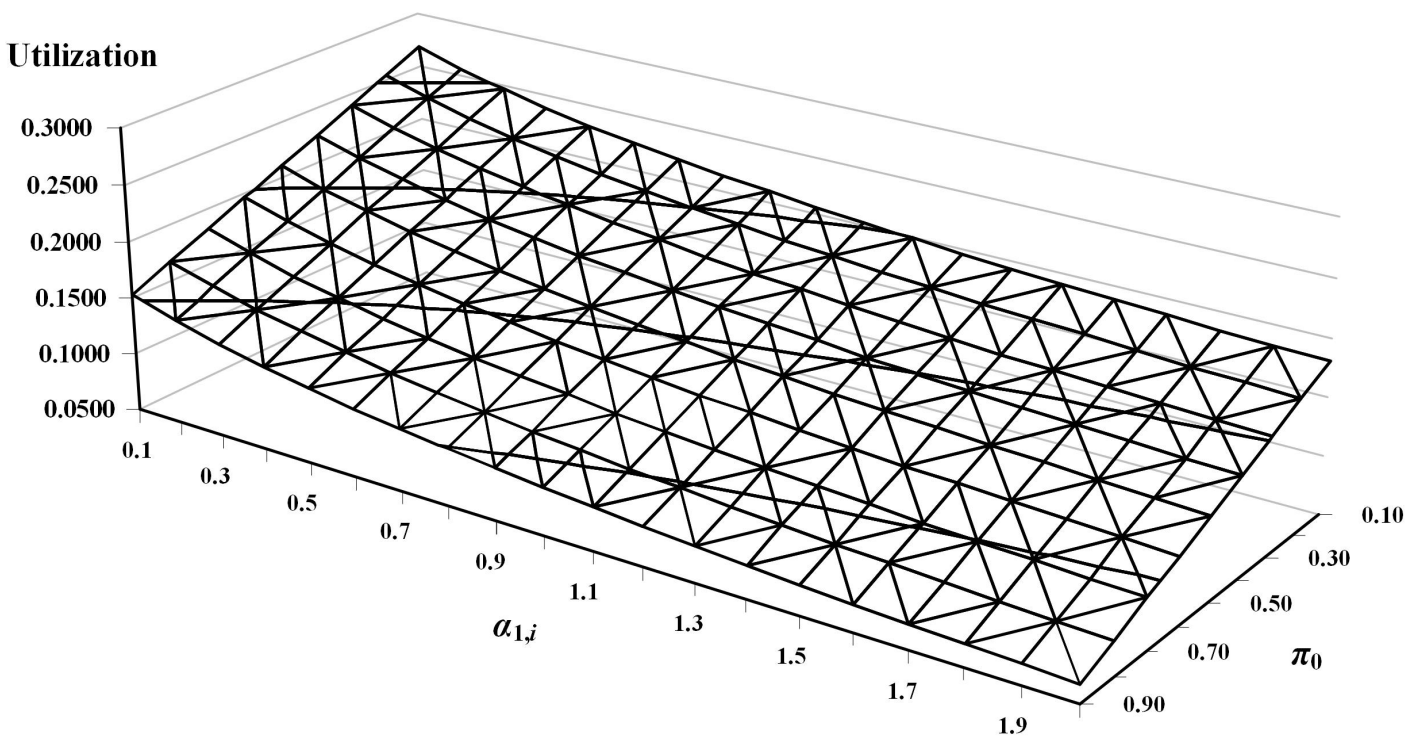

Figure 5: The combined effect of $\alpha_{1, i}$ and $\pi_{0}$ on utilization

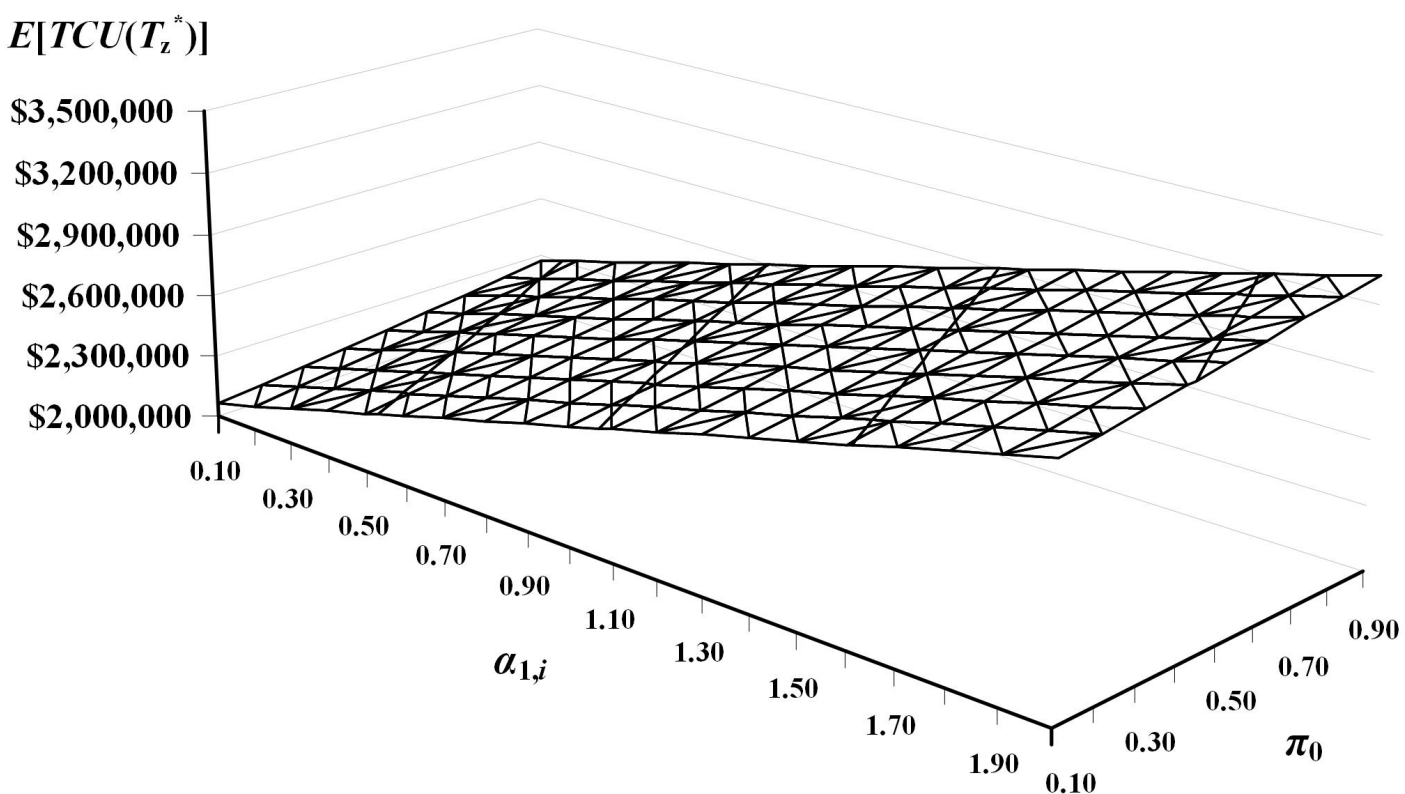

Figure 6: The joint influence of $\alpha_{1, i}$ and $\pi 0$ on $\operatorname{E}\left[\operatorname{TCU}\left(T_{z}^{*}\right)\right]$

\section{Dual fabrication-time reduction strategies effect on the problem}

The proposed model presents dual fabrication time reduction strategies, namely, outsourcing the common parts in stage 1 and the expedited-rate for making end items in stage 2. The individual impact of these strategies on the studied problem is explored below. Figure 7 exhibits the analytical result of the impact of outsourcing portion $\pi_{0}$ on the sum of uptime and rework time (i.e., $t_{0}{ }^{*}$, in stage one). It exposes that when the common parts' outsourcing portion is $40 \%$, the total fabrication time $t_{0}^{*}$ declines from 0.0824 years to 0.0513 years, or a $37.7 \%$ drop (see Table C-1 in Appendix C).

Figure 8 illustrates the analytical results on the changes in $E\left[T C U\left(T_{Z}^{*}\right)\right]$ and its contributors concerning the outsourcing portion $\Pi_{0}$. It specifies that as the outsourcing portion $\pi_{0}$ increases, the common part's outsourcing cost surges significantly, relatively, the in-house common part's variable cost decreases considerably. All other cost contributors to $E\left[T C U\left(T_{z}^{*}\right)\right]$ have a trivial effect concerning $\pi_{0}$. At $\pi_{0}=0.4$, the price we pay to reduce $t_{0}{ }^{*}$ by $37.7 \%$ is $4.77 \%$ in total cost increase. That is, $E\left[T C U\left(T_{Z}^{*}\right)\right]$ rises from $\$ 2,252,391$ to $\$ 2,359,729$ (for details, please refer to Table C-1 in Appendix C).

Figure 9 depicts the influence of the expedited-rate factor $\alpha_{1,}$ on the sum of uptime and rework time of end items (i.e., $t_{i}^{*}$, in stage two). It discloses that at the expedited-rate factor $\alpha_{1, i}=0.5$, the total fabrication time $t_{i}^{*}$ drops a $30.3 \%$ (i.e., it declines from 0.0868 years to 0.0605 ; see Table C-1 in Appendix C for details).

Figure 10 exhibits the investigative outcomes of changes in $E\left[T C U\left(T_{z}^{*}\right)\right]$ concerning the expedited-rate factor $\alpha_{1, i}$ At $\alpha_{1, i}=0.5$, it indicates that the price we pay to reduce $t_{i}^{*}$ by $30.3 \%$ is $13.36 \%$ in total cost increase. That 


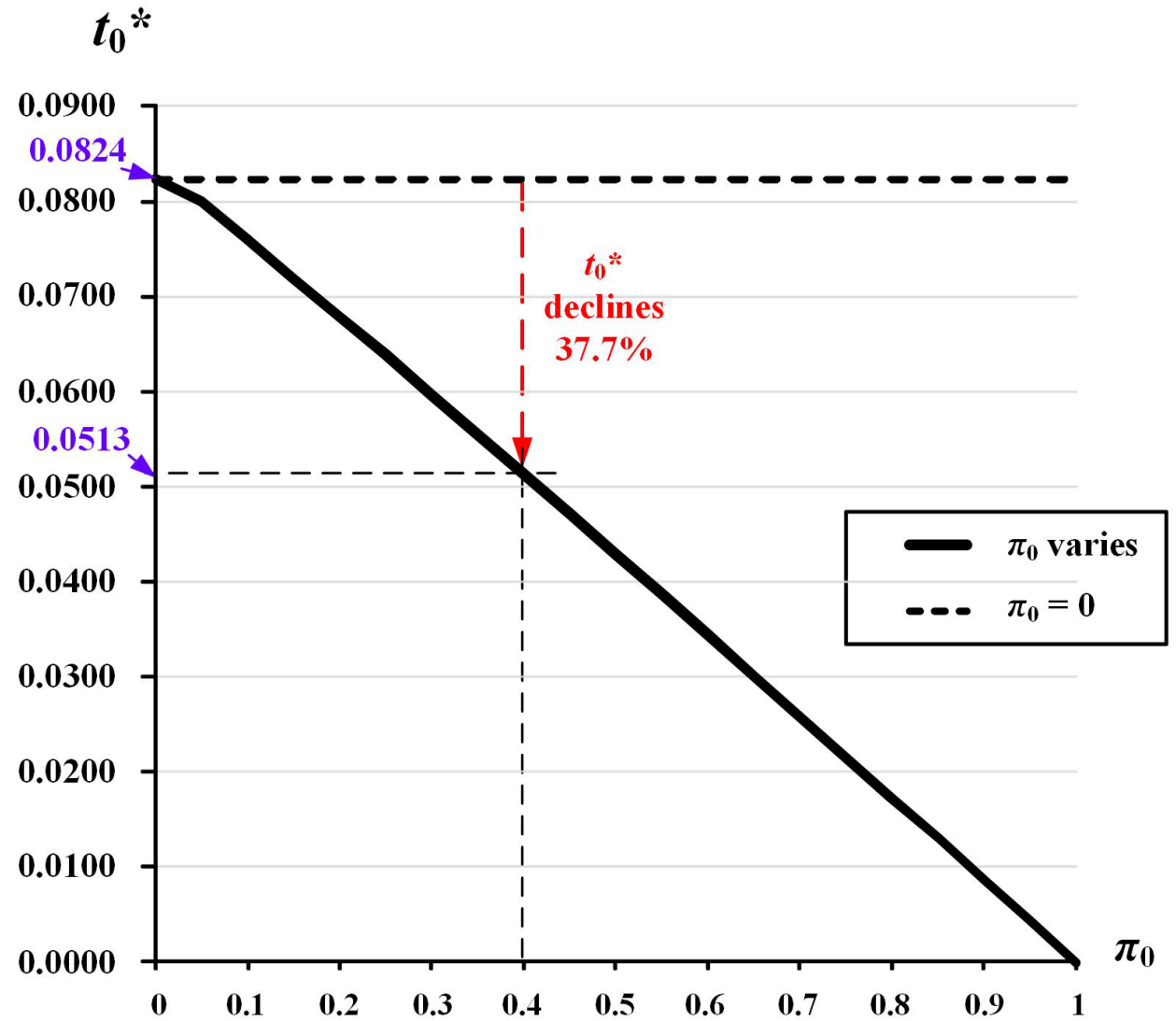

Figure 7: Impact of outsourcing portion $\pi_{0}$ on the sum of uptime and rework time $t_{0}^{*}$

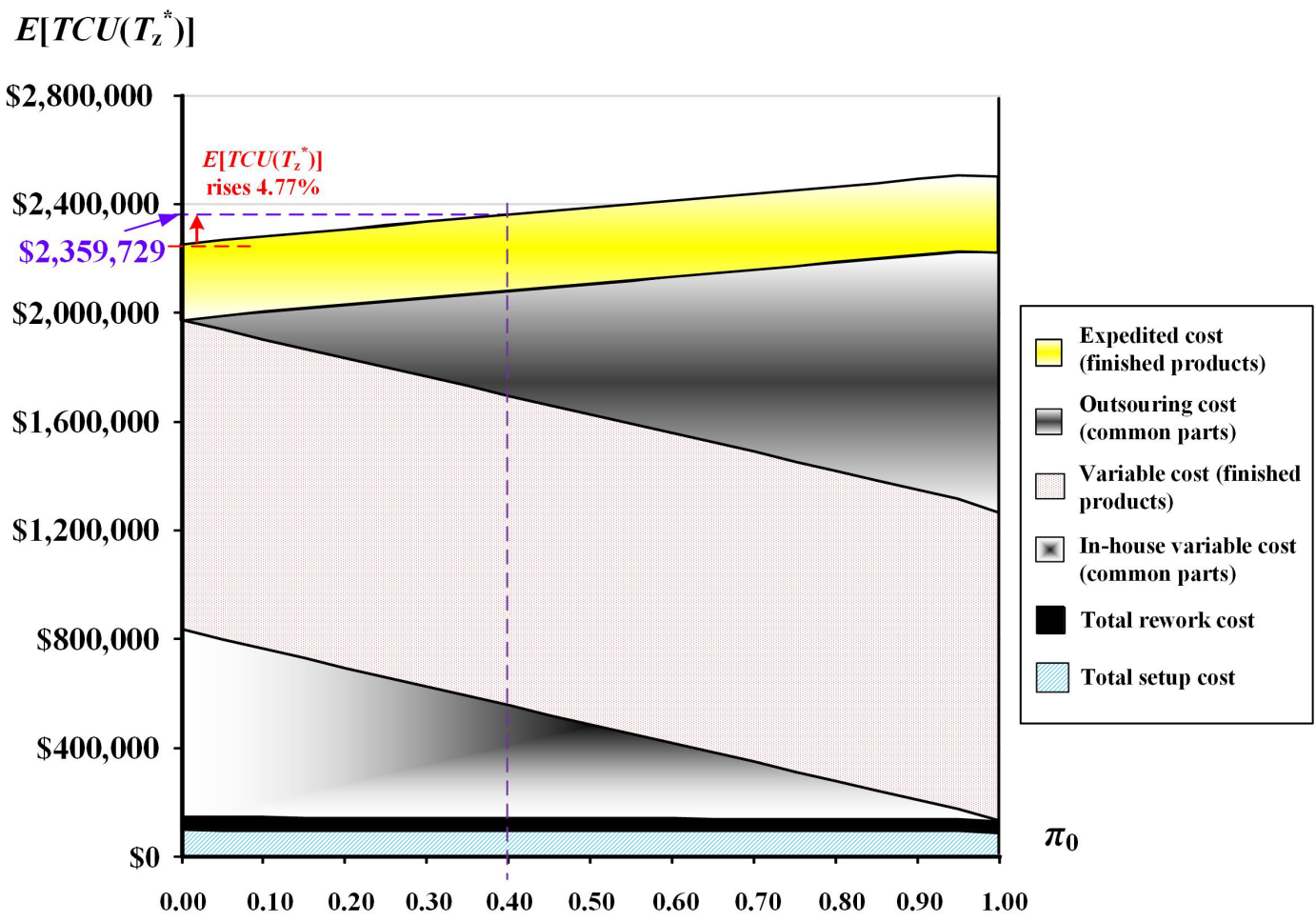

Figure 8: Changes in $E\left[T C U\left(T_{z}^{*}\right)\right]$ and its contributors concerning the outsourcing portion $\pi_{0}$ 


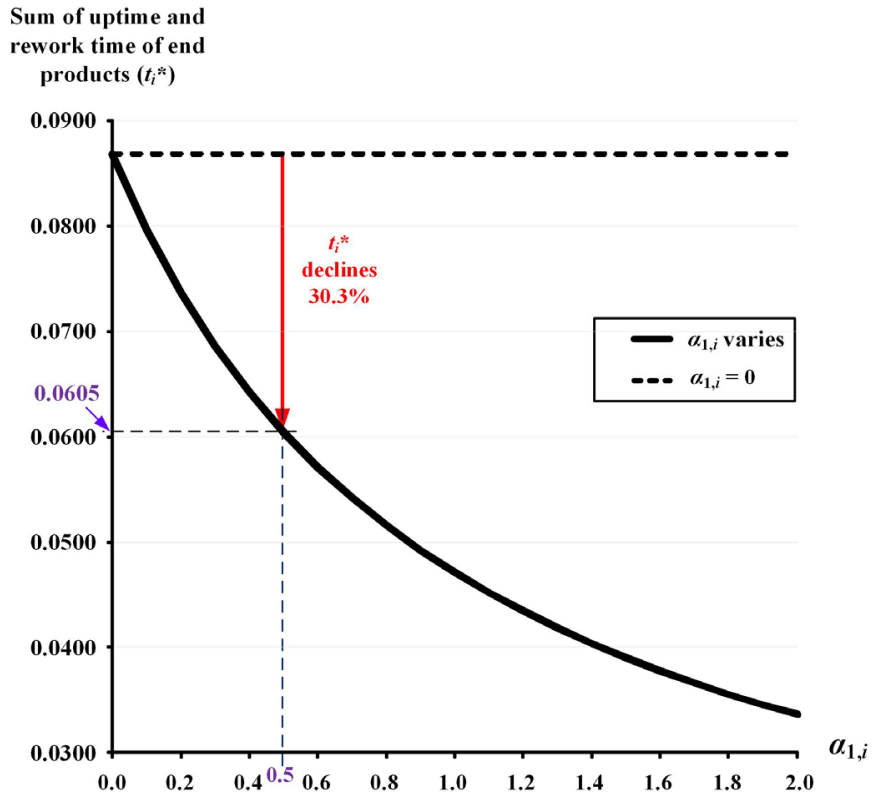

Figure 9: The influence of expedited-rate factor $\alpha_{1, i}$ on the sum of uptime and rework time $t_{i}^{*}$

$\operatorname{E}\left[\operatorname{TCU}\left(T_{z}^{*}\right)\right]$

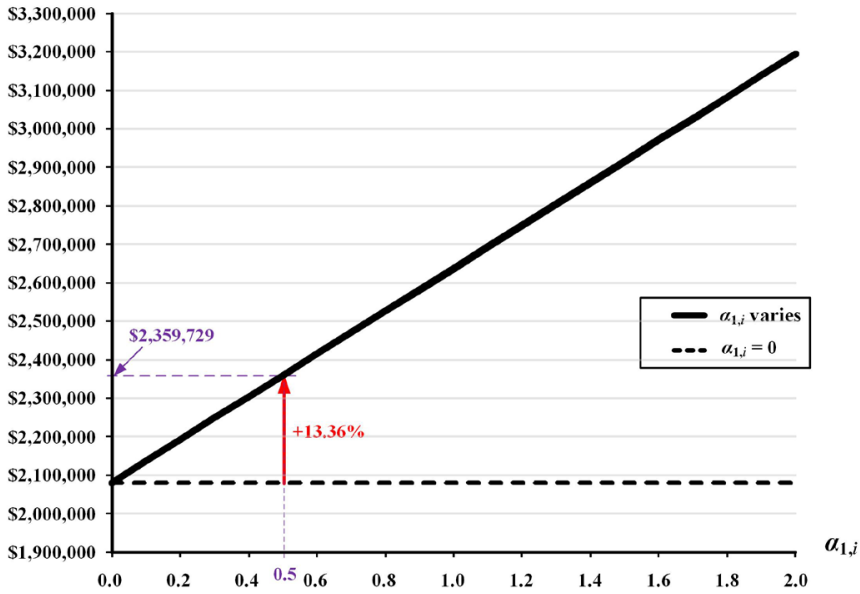

Figure 10: Changes in $E\left[T C U\left(T_{z}^{*}\right)\right]$ concerning the expedited-rate factor $\alpha_{1, i}$

is, $E\left[T C U\left(T_{z}^{*}\right)\right]$ rises from $\$ 2,081,646$ to $\$ 2,359,729$ (for details, please see Table C-1 in Appendix C).

The individual and combined impact of $\alpha_{1 i}$ and $\pi_{0}$ on $E[T-$ $\left.C U\left(T_{z}^{*}\right)\right]$ are explicitly explored and exhibited in Figure 11. According to our parameter assumptions, to effectively reduce the fabrication time/machine utilization, it is more economical to start with outsourcing $40 \%$ common parts (in stage 1) and, in the meantime, gradually expedite the fabrication rate for end items in stage 2. Once $\alpha_{1}$ reaches 0.5 (while $\pi_{0}$ remains at 0.4 ), to further reduce utilization, it is more economical to keep $\alpha_{1, i}$ at 0.5 and start to increase the outsourcing factor $\pi_{0}$ solely. One thing worth to mention is that our proposed model can conduct a similar investigation for any given parameter assumptions to provide in-depth analytical information for managerial decision-making needs.

\section{Investigating the effect of rework and cost relevant issues on the problem}

The variations of $E\left[T C U\left(T_{z}^{*}\right)\right]$ concerning the ratio of average rework cost vs. average unit cost are investigated and illustrated in Figure 12. It merely shows that $E\left[T C U\left(T_{z}^{*}\right)\right]$ surges noticeably as the ratio of average rework over unit costs rises. Our example assumes the ratio is 0.6 ; the optimal $E\left[\operatorname{TCU}\left(T_{Z}^{*}\right)\right]$ is $2,359,729$.

Figure 13 depicts the investigative results of cost contributors to $E\left[\operatorname{TCU}\left(T_{z}^{*}\right)\right]$. It reveals that total rework costs add up to $2.00 \%$ (i.e., $0.14 \%$ for reworking common parts and $1.86 \%$ for reworking end products; please see Tables C-1 and C-2 for details). The in-house variable cost for common parts and end products contribute $17.55 \%$ and $48.32 \%$ of $E\left[T C U\left(T_{z}^{*}\right)\right]$, respectively. The relevant expedited-rate and outsourcing costs contribute $11.82 \%$ and $16.32 \%$ of $E\left[T C U\left(T_{z}^{*}\right)\right]$, respectively.

Figure 14 demonstrates that our model can explore other previously inaccessible crucial system information, such as each end product's variable cost concerning the expedited-rate factor $\alpha_{1, i}$. It discloses that each end item's variable cost surges, as $\alpha_{1, i}$ ises.

\section{$\operatorname{E}\left[\operatorname{TCU}\left(T_{\mathrm{z}}^{*}\right)\right]$}

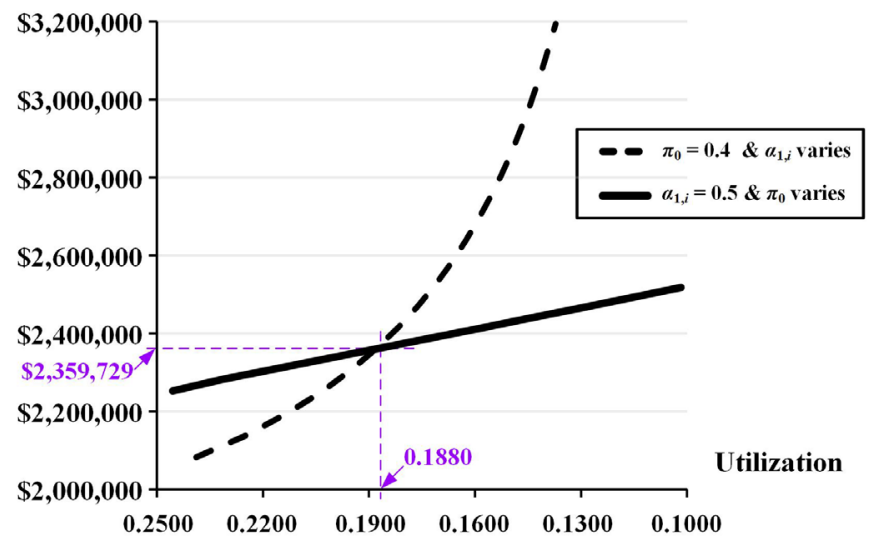

Figure 11: The individual and combined impact of $\pi_{0}$ and $\alpha_{1, i}$ on $\operatorname{E}\left[\operatorname{TCU}\left(T_{Z}^{*}\right)\right]$

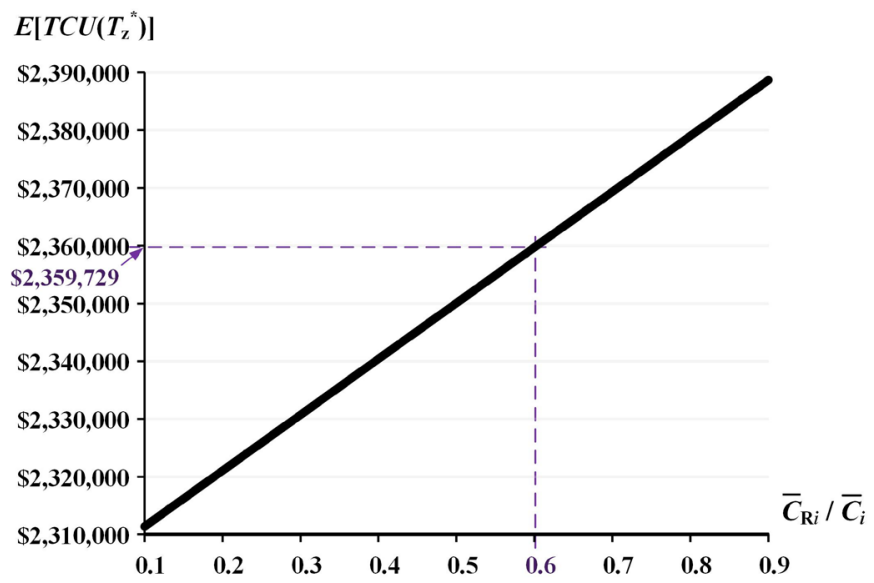

Figure 12: The variations of $E\left[T C U\left(T_{z}^{*}\right)\right]$ concerning the ratio of average rework cost versus unit cost 


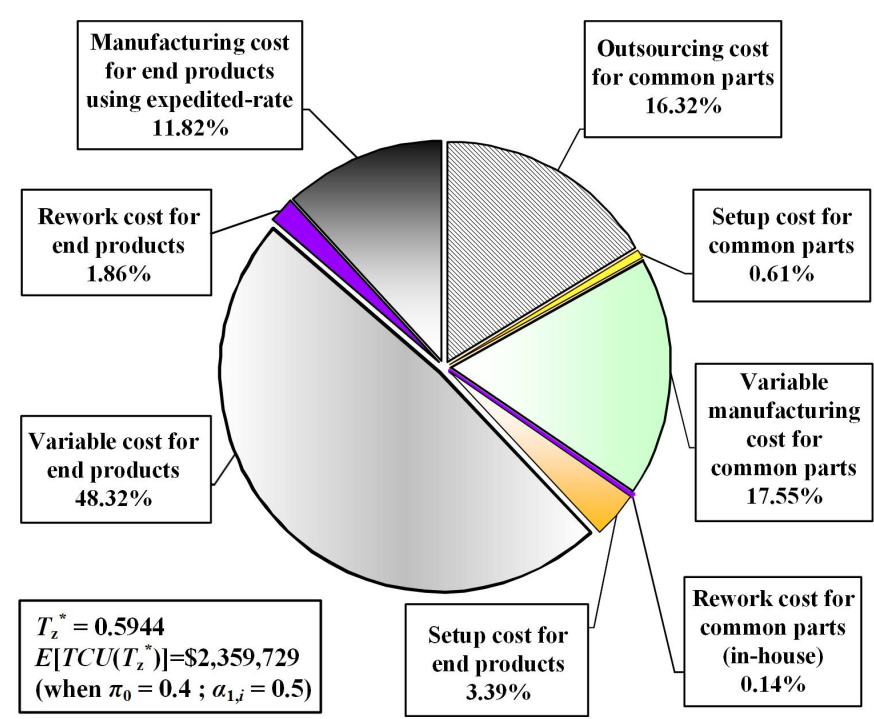

Figure 13: The breakup of $E\left[T C U\left(T_{z}^{*}\right)\right]$

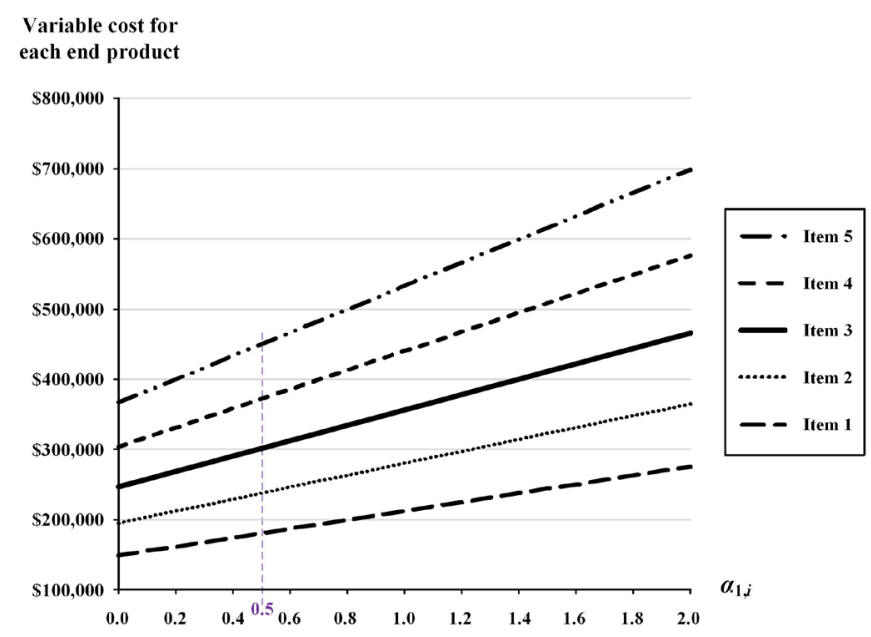

Figure 14: Each end item's variable cost concerning the expedited-rate factor $\alpha_{1, i}$

\section{Effect of the common part's completion rate on the problem}

Figure 15 explores the effect of the common part's completion rate $\mathrm{y}$ on the optimal sum of uptime plus rework time $t_{0}{ }^{*}$. It exposes that the optimal $t_{0}{ }^{*}$ significantly surges as $y$ rises. At our assumption where $y=0.5$, it shows that $t_{0}^{*}=0.0513$ (please refer to Table C-1 in Appendix C). Table C- 1 also shows that for $y=0.5$, by outsourcing $40 \%$ of common parts, $t_{0}^{*}$ declines from 0.0824 to 0.0513 (or a $37.7 \%$ drop).

Figure 16 exhibits the influence of the linear (i.e., $\delta=\gamma_{1}$ ) and nonlinear (e.g., $\delta=\gamma_{3}$ ) relationships between $\delta$ and $\gamma$ on the optimal decision variable $T_{z}{ }^{*}$. It not only verifies our example that when $\gamma=0.50, T_{z}^{*}=0.5944$ (see Table C-1 in Appendix C), but also reveals the crucial information of $T_{Z}{ }^{*}$ variations relating to the nonlinear relationships between $\delta$ and $\gamma$.

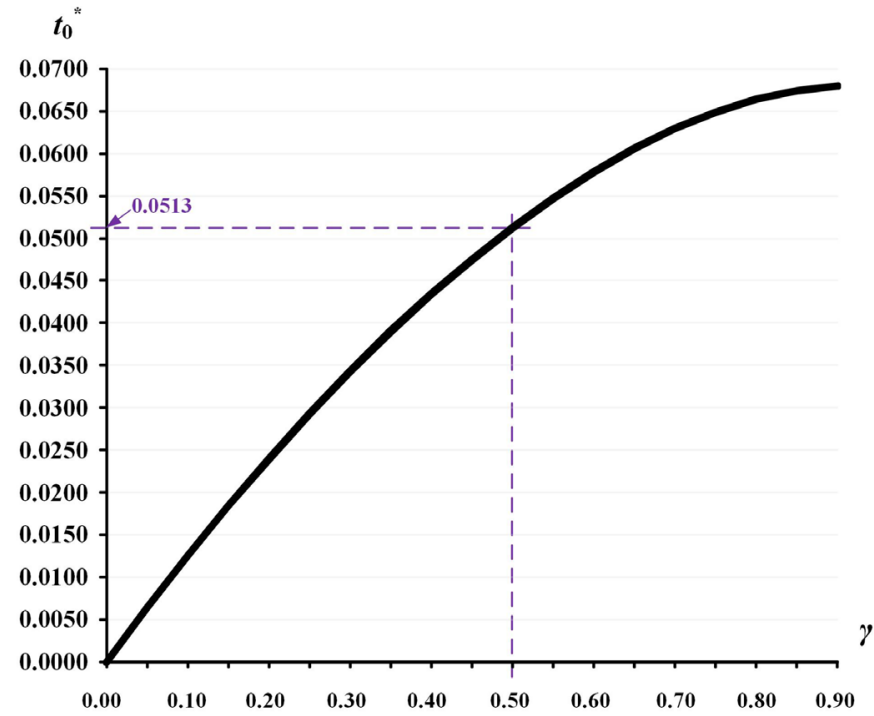

Figure 15: Changes of the optimal sum of uptime plus rework time $t_{0}{ }^{*}$ concerning $\mathrm{V}$

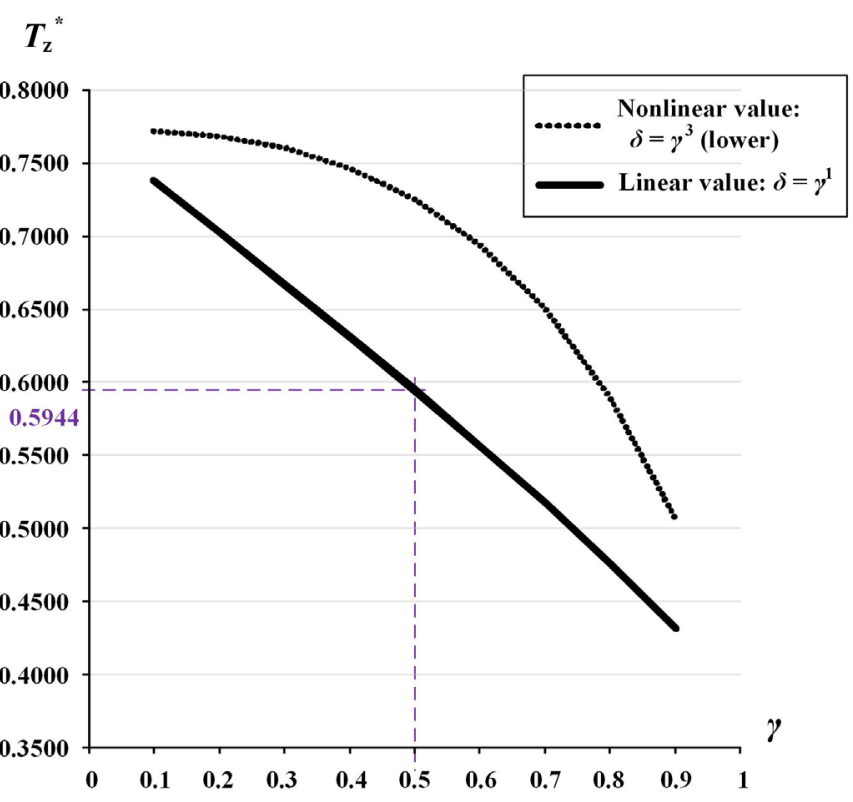

Figure 16: The impact of the linear/nonlinear relationships between $\delta$ and $y$

\section{Comparison among closely-related models}

Figure 17 compares our model's utilization with other closely-related models. Since we implement both outsourcing and expedited-rate strategies, our model results in the lowest utilization (i.e., 0.1880 ). It is $21.3 \%$ lower than a model with solely outsourcing common parts, and our utilization is $36.6 \%$ lower than a similar model without neither outsourcing nor expedited-rate strategies.

Figure 18 compares our study's $E\left[T C U\left(T_{z}^{*}\right)\right]$ with other closely-related models. It exposes that through implementing both outsourcing and expedited-rate strategies to reduce our utilization to 0.1880 , we are paying the price of a $13.36 \%$ or $19.54 \%$ surge in $E\left[T C U\left(T_{z}^{*}\right)\right]$. This critical information is now available to managers to facilitate their fabrication planning and management. 


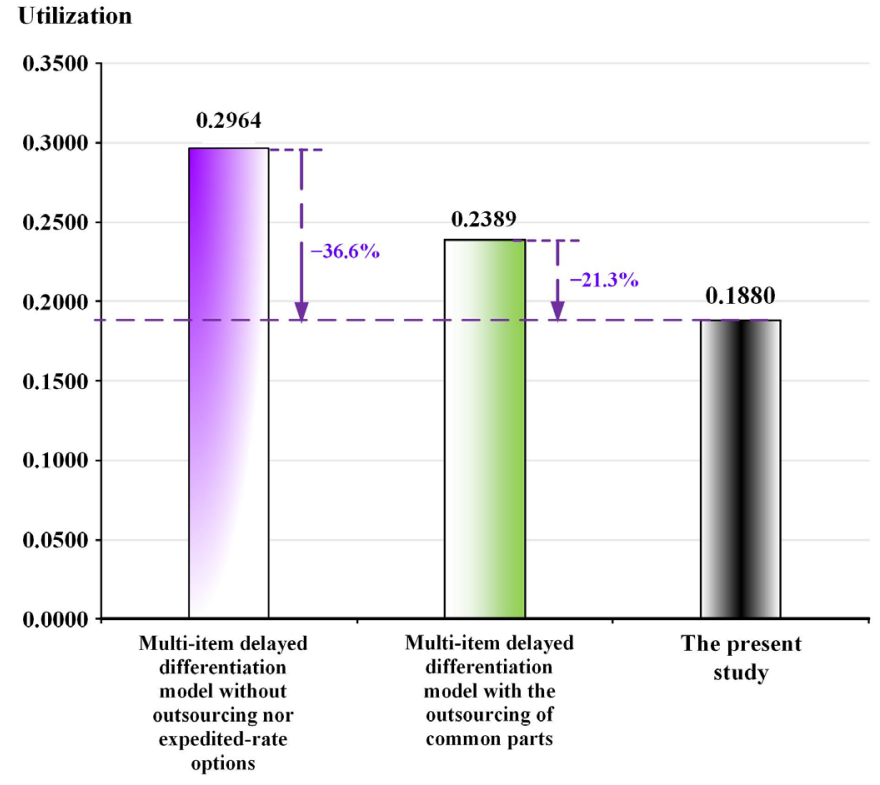

Figure 17: Comparison of our model's utilization with other closely-related models

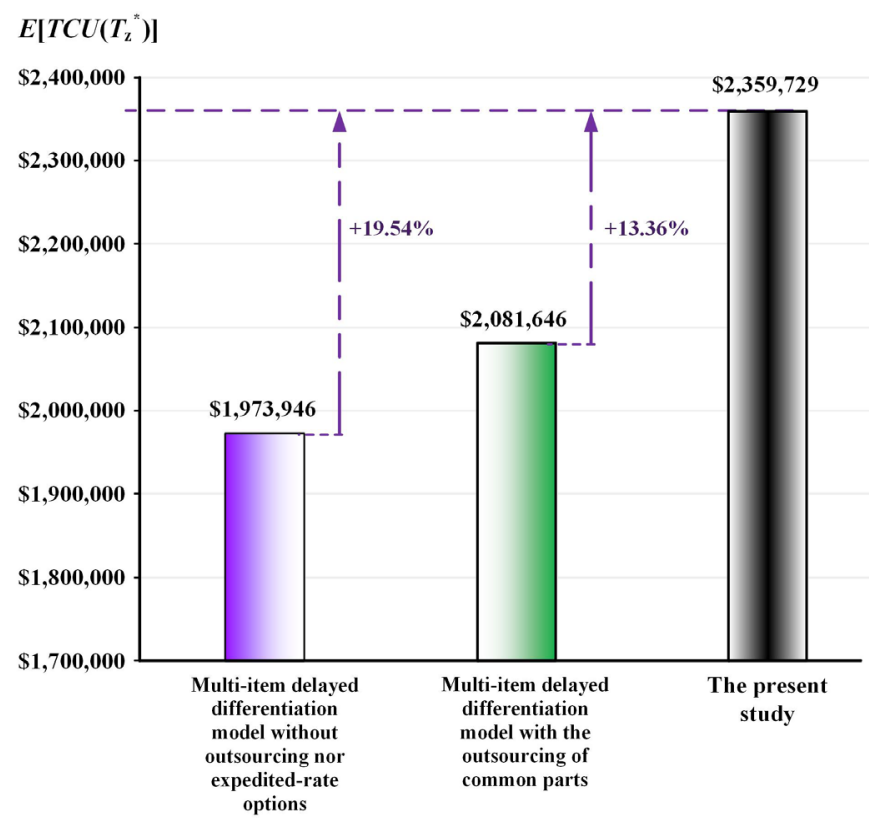

Figure 18: Comparison of our model's $E\left[T C U\left(T_{z}^{*}\right)\right]$ with other closely related models

\section{CONCLUSIONS}

This study develops a decision model to explore a multiitem delayed-differentiation production system featuring commonality, outsourcing, expedited rate, and rework. It aims to help manufacturers meet clients' timely multiproduct needs in conditions of restricted-capacity and minimum total operating expenses. We adopt a twostage delayed-differentiation scheme to manage the end products' commonality, dual uptime-reduction strategies to shorten total fabrication time, and rework process to assure product quality. Mathematical analysis with optimization helps prove the cost function's convexity and determine the cost-minimization rotation cycle policy (re- fer to equations (27) to (29)). Finally, we use a simulated example to numerically validate the model's and results' applicability and capability (refer to Figures 4 to 18).

Apart from creating a useful decision model, this study makes another important contribution to the existing literature in that its revelation of collective/individual effect of the manufacturing-relevant strategies on the problem's best-operating cycle policy and crucial performance indices helps manufacturers better control their operations and make effective and efficient managerial decisions.

Our research results expose that the system-features effect on the problem's operating policy, from the most to the least following the sequence below: outsourcing, expedited-rate, common part's completion rate, and reworking cost. These findings are consistent with prior studies. Figures 17 and 18 demonstrate a few comparing results with previous works.

Besides, to the researchers in the same field, our analytical model outperforms prior works in that it can determine: (I) for any given cost-relevant parameters, which strategy (either the expediting-rate or the outsourcing) is more effective and economical to reduce the system's utilization, as illustrated in Figure 11; (II) the best-operating cycle length for given linear or nonlinear relationships of the common part's value and its completion rate, as depicted in Figure 16; (III) the best common part's fabrication uptime plus rework time, for any given common part's completion rate, as demonstrated in Figure 15; and (iv) the various collective and individual effects of manufacturing-relevant factors on the problem's crucial performance indices, as exhibited in Figures 7 to 10, 12, and 14. Our study and results may inspire researchers in other fields and the general public regarding the potential usage of mathematical modeling to resolve their fields' specific problems.

For future research, incorporating an end-products' multi-shipment plan in the proposed problem is worth investigating.

\section{ACKNOWLEDGMENT}

This work is sponsored by the Ministry of Science and Technology of Taiwan (Grant \#: MOST 109-2221-E-324-015).

\section{REFERENCES}

1. Silver, E.A., Minner, S. (2005). A replenishment decision involving partial postponement. OR Spectrum, 27 (1), 1-19. https://doi.org/10.1007/s00291-0040175-5

2. Kuthambalayan, T.S., Mehta, P., Shanker, K. (2014). Integrating operations and marketing decisions using delayed differentiation of products and guaranteed delivery time under stochastic demand. European Journal of Operational Research, 237, 617-627. https://doi.org/10.1016/j.ejor.2014.01.055 
3. Prataviera, L.B., Perotti, S., Melacini, M., Moretti, E. (2020). Postponement Strategies for Global Downstream Supply Chains: A Conceptual Framework. Journal of Business Logistics, 41, 94-110. https://doi. org/10.1111/jbl.12250

4. Zinn, W. (2019). A Historical Review of Postponement Research. Journal of Business Logistics, 40, 66-72. https://doi.org/10.1111/jbl.12213

5. Chiu, S.W., Zhao, Z-Y., Chiu, T., Chiu, Y-S.P. (2020). Combining the delayed differentiation policy and common parts' partial outsourcing strategy into a multi-item FPR-based system. Journal of Applied Engineering Science, 18(2), 273-280. https://doi. org/10.5937/jaes18-23877

6. Galizia, F.G., ElMaraghy, H.A., Bortolini, M., Mora, C. (2020). Product platforms design, selection and customisation in high-variety manufacturing. International Journal of Production Research, 58, 893-911. https://doi.org/10.1080/00207543.2019.1602745

7. Chiu, S.W., Lin, J-N., Wang, Y., Lin, H-D. (2020). Mathematical modeling for multiproduct EPQ problem featuring delayed differentiation, expedited rate, and scrap. International Journal for Engineering Modelling, 33 (3-4), 75-95. https://doi.org/10.31534/ engmod.2020.3-4.ri.05v

8. Lee, Y-H., Wei, C-C., Chen, C-B., Tsai, C-H. (2000). Minimization of scrap and rework costs by process tolerances allocation. Engineering Optimization, 32 (5), 619-633. https://doi. org/10.1080/03052150008941315

9. Pasandideh, S.H.R., Niaki, S.T.A., Mirhosseyni, S.S. (2010). A parameter-tuned genetic algorithm to solve multi-product economic production quantity model with defective items, rework, and constrained space. International Journal of Advanced Manufacturing Technology, 49, 827-837. https://doi.org/10.1007/ s00170-009-2432-x

10. Nobil, A.H., Afshar Sedigh, A.H., Tiwari, S., Wee, H.M. (2019). An imperfect multi-item single-machine production system with shortage, rework, and scrap considering inspection, dissimilar deficiency levels, and non-zero setup times. Scientia Iranica, 26, 557570. https://dx.doi.org/10.24200/sci.2018.4984.1031

11. Zhetessova, G., Yurchenko, V., Nikonova, T., Zharkevich, O. (2019). The development of the computer-aided design system for production processes of component part machining for single-piece production and repair conditions. Journal of Applied Engineering Science, 17 (4), 599-609. https://doi. org/10.5937/jaes17-21470

12. Ortiz-Servin, J.J., Castillo, A., Talavera, F. (2019). A new methodology to optimize operation cycles in a bwr using heuristic techniques. Journal of Applied Research and Technology, 17 (3), 155-162. https:// doi.org/10.22201/icat.16656423.2019.17.3.808
13. Chiu, Y-S.P., Sung, P-C., Chiu, V. (2020). A twophase solution approach for a manufacturing-distribution problem with rework, outsourcing, and multi-shipment policy. Journal of Applied Engineering Science 18(4), 505-509. https://doi.org/10.5937/ jaes0-26156

14. Chiu, S.W., You, L-W., Sung, P-C., Wang, Y. (2020). Determining the fabrication runtime for a buyer-vendor system with stochastic breakdown, accelerated rate, repairable items, and multi-delivery strategy. International Journal of Industrial Engineering Computations, 11(4): 491-508. http://dx.doi.org/10.5267/j. ijiec.2020.6.002

15. Sung, C.S., Han, Y.H. (1993). Optimal buffer space for a periodic review production/inventory system with inventory-dependent production rate. International Journal of Production Economics, 29 (1), 1125. https://doi.org/10.1016/0925-5273(93)90020-L

16. Lehtinen, U. (1999). Subcontractors in a partnership environment: a study on changing manufacturing strategy. International Journal of Production Economics, 60, 165-170. https://doi.org/10.1016/S09255273(98)00154-6

17. Momme, J., Hvolby, H-H. (2002). An outsourcing framework: action research in the heavy industry sector. European Journal of Purchasing \& Supply Management, 8(4), 185-196. https://doi.org/10.1016/ S0969-7012(02)00003-5

18. Soni, H.N., Patel, K.A. (2012). Optimal strategy for an integrated inventory system involving variable production and defective items under retailer partial trade credit policy. Decision Support Systems, 54 (1), 235-247. https://doi.org/10.1016/j.dss.2012.05.009

19. Akkermans, H., Van Oppen, W., Wynstra, F., Voss, C. (2019). Contracting outsourced services with collaborative key performance indicators. Journal of Operations Management, 65 (1), 22-47. https://doi. org/10.1002/joom.1002

20. Toncovich, A.A., Rossit, D.A., Frutos, M., Rossit, D.G. (2019). Solving a multi-objective manufacturing cell scheduling problem with the consideration of warehouses using a simulated annealing based procedure. International Journal of Industrial Engineering Computations, 10 (1), 1-16. http://dx.doi. org/10.5267/j.ijiec.2018.6.001

21. Chiu, S.W., Huang, Y-J., Chou, C-L., Chiu, Y-S.P. (2020). Manufacturing runtime problem with an expedited fabrication rate, random failures, and scrap. International Journal of Industrial Engineering Computations, 11(1): 35-50. http://dx.doi.org/10.5267/j. ijiec.2019.6.006 
22. Chiu, Y.-S.P., Zhao, Z.-Y., Chiu, S.W., Chiu, V. (2020). A vendor-buyer coordinated system featuring an unreliable machine, scrap, outsourcing, and multiple shipments. International Journal of Industrial Engineering Computations, 11(3), 341-358. http:// dx.doi.org/10.5267/j.ijiec.2020.1.004

23. Dekker, H.C., Mooi, E., Visser, A. (2020). Firm enablement through outsourcing: A longitudinal analysis of how outsourcing enables process improvement under financial and competence constraints. Industrial Marketing Management, 90, 124-132. https://doi.org/10.1016/j.indmarman.2020.07.006

24. Nahmias, S. (2009). Production \& Operations Analysis. McGraw-Hill Inc. New York.

\section{NOMENCLATURE}

$\lambda_{i}=$ annual demand of end item $\mathrm{i}$ (where $\left.i=1,2, \ldots, L\right)$,

$Q_{i}=$ lot size for product $i$,

$T_{z}=$ the replenishment cycle length (i.e., the decision variable of our study),

$\lambda_{0}=$ annual demand of the common parts,

$Q_{0}=$ in-house lot size for common parts in stage 1,

$t_{1,0}=$ common parts' uptime,

$t_{2,0}=$ common parts' rework time,

$t_{3,0}=$ common parts' consumption time,

$H_{1,0}=$ stock level of common parts when uptime ends,

$H_{2,0}=$ stock level of common parts when rework process ends,

$H_{3,0}=$ stock level of common parts upon receipt of the outsourced items,

$t_{0}^{*}=$ the sum of common parts' optimal uptime and rework time,

$I(t)_{i}=$ stock level at time $t$ (where $\left.i=0,1,2, \ldots, L\right)$,

$\pi_{0}=$ the outsourcing portion of the lot size of common parts,

$K_{0}=$ common part's in-house setup cost,

$K_{\pi_{0}}=$ fixed cost of outsourcing, where $K_{\pi 0}=K_{0}\left(1+\beta_{1,0}\right)$,

$\beta_{1,0}=$ the linking factor between $K_{\pi 0}$ and $K_{0}$,

$C_{0}=$ common part's in-house unit cost,

$C_{\pi 0}=$ common part's unit outsourcing cost, where $C_{\pi 0}=C_{0}$

$\left(1+\beta_{2,0}\right)$,

$\beta_{2,0}=$ the linking factor between $C_{\pi 0}$ and $C_{0}$,

$P_{1,0}=$ common part's annual manufacturing rate,

$x_{0}=$ common part's random defective rate,

$d_{1,0}=$ manufacturing rate of defective common parts, where $d_{1,0}=P_{1,0} x_{0}$,

$P_{2,0}=$ annual reworking rate of defective common parts,

$C_{R, 0}=$ common part's unit rework cost,

$h_{1,0}=$ common part's unit holding cost,

$h_{2,0}=$ unit holding cost of reworked common parts,

$h_{4,0}=$ safety common part's unit holding cost, $i_{0}=$ the cost ratio of holding cost (e.g., $h_{1,0}=i_{0} C_{0}$ ),

$\gamma=$ the common part's completion rate compared with the finished item,

$H_{i}=$ stock level of common parts when the uptime of product i ends,

$S_{0}=$ setup time of common part,

$t_{1, i}=$ uptime of end product $i$,

$t_{2, i}=$ rework time of end product $i$,

$t_{3, i}=$ consumption time of end product $i$,

$\mathrm{H}_{1, i}$ =stock level of end product $i$ when its uptime completes,

$H_{2, i}=$ stock level of end product i when its rework ends,

$t_{i}^{*}=$ the optimal total uptimes of the end products (in stage two),

$S_{i}=$ setup time of end product $i$,

$P_{1, i}=$ standard annual manufacturing rate of end product $i$,

$P_{T 1, i}=$ expedited rate for end product $i$, where $P_{T 1, i}=P_{1, i}$ $\left(1+\alpha_{1, i}\right)$,

$\alpha_{1, i}=$ the linking factor between $P_{T 1, i}$ and $P_{1, i}$,

$x_{i}=$ random defective rate of end item $i$,

$P_{2, i}=$ standard annual rework rate for end product $i$,

$P_{\mathrm{T} 2, i}=$ annual expedited rework rate for end product $i$, where $P_{T 2, i}=P_{2, i}\left(1+\alpha_{1, i}\right)$,

$\mathrm{d}_{\mathrm{T} 1, i}=$ manufacturing rate of defective end product $i$, where $\left.d_{T 1, i}=P_{T 1, i} x_{i}\right)$,

$K_{i}=$ standard setup cost for end product $i$,

$K_{T,}=$ setup cost for end product i when expedited rate is implemented, where $K_{T, i}=K_{i}\left(1+\alpha_{2, i}\right)$

$\alpha_{2, i}=$ the linking factor between $K_{T, i}$ and $K_{i}$,

$C_{i}=$ standard unit manufacturing cost of end product $i$,

$C_{T, i}=$ unit manufacturing cost of end product i when expedited rate is implemented, where $C_{T, i}=C_{i}\left(1+\alpha_{3, i}\right)$,

$\alpha_{3, i}=$ the linking factor between $C_{T, i}$ and $C_{i}$,

$C_{R, i}=$ standard unit rework cost for end product $\mathrm{i}$,

$C_{T R, i}=$ unit rework cost for end product i when expedited rate is implemented, where $C_{T R, i}=C_{R, i}\left(1+\alpha_{3, i}\right)$,

$h_{1, i}=$ holding cost of end product $\mathrm{i}$,

$h_{2, i}=$ holding cost per reworked end product i,

$h_{4, i}=$ unit holding cost for the safety end product $\mathrm{i}$,

$T C\left(T_{z}\right)=$ total cost per replenishment cycle,

$E\left[T C\left(T_{z}\right)\right]=$ the expected total cost per replenishment cycle, $E\left[T_{Z}\right]=$ the expected rotation replenishment cycle length, $E\left[\operatorname{TCU}\left(T_{z}\right)\right]=$ the expected cost per unit time.

\section{APPENDIX - A}

The following are detailed derivations of Eq. (26):

First, apply the expected values $E\left[x_{0}\right]$ and $E\left[X_{i}\right]$ (where $i=1,2, \ldots, L)$ to cope with random nonconforming rates. Then, replace Eqs. (1) to (24) in $T C\left(T_{z}\right)$. Finally, apply $E\left[T C\left(T_{z}\right)\right] / E\left[T_{z}\right]$, and with additional derivation efforts, we 
derive $E\left[T C U\left(T_{z}\right)\right]$ as follows:

$$
\begin{aligned}
& E\left[\operatorname{TCU}\left(T_{z}\right)\right]=\left\{\begin{array}{l}
\frac{\left(1+b_{1,0}\right) K_{0}}{T_{z}}+\left(1+\beta_{2,0}\right) C_{0} \pi_{0} \lambda_{0}+C_{0}\left(1-\Pi_{0}\right) \lambda_{0}+\frac{K_{0}}{T_{z}}+C_{R, 0} E\left[x_{0}\right]\left(1-\Pi_{0}\right) \lambda_{0} \\
+\frac{h_{2,0} \lambda_{0}^{2} E\left[x_{0}\right]^{2}\left(1-\Pi_{0}\right)^{2} T_{z}}{2 P_{2,0}}+\frac{h_{1,0} \lambda_{0}^{2}\left(1-\Pi_{0}\right)^{2} T_{z}}{2}\left[\frac{1}{P_{1,0}}+\frac{E\left[x_{0}\right]\left[2-E\left[x_{0}\right]\right]}{P_{2,0}}\right] \\
+h_{1,0} \sum_{i=1}^{L}\left\{\frac{\lambda_{i}^{2} T_{z}}{2\left(1+\alpha_{1, i}\right) P_{1, i}}+\left(\sum_{i=1}^{L}\left(\lambda_{i} T_{z}\right)-\sum_{j=1}^{i}\left(\lambda_{j} T_{z}\right)\right) \lambda_{i}\left[\frac{1}{\left(1+\alpha_{1, i}\right) P_{1, i}}+\frac{E\left[x_{i}\right]}{\left(1+\alpha_{1, i}\right) P_{2, i}}\right]\right.
\end{array}\right\} \\
& +\sum_{i=1}^{L}\left\{\begin{array}{l}
\left(1+\alpha_{3, i}\right) C_{i} \lambda_{i}+\frac{\left(1+\alpha_{2, i}\right) K_{i}}{T_{z}}+\left(1+\alpha_{3, i}\right) C_{R, i} E\left[x_{i}\right] \lambda_{i} \\
+h_{2, i}\left[\frac{E\left[x_{i}\right]^{2} \lambda_{i}^{2} T_{z}}{2\left(1+\alpha_{1, i}\right) P_{2, i}}\right]+h_{1, i}\left[\frac{\lambda_{i}^{2} T_{z}}{2}\right]\left[\frac{1}{\lambda_{i}}-\frac{1}{\left(1+\alpha_{1, i}\right) P_{1, i}}-\frac{E\left[x_{i}\right]^{2}}{\left(1+\alpha_{1, i}\right) P_{2, i}}\right]
\end{array}\right\}
\end{aligned}
$$

Let $E_{O P}, E_{0 \pi}, E_{1 i}, E_{2 i}$, and $E_{3 i}$ be as follows:

$E_{0 P}=\left[\frac{1}{P_{1,0}}+\frac{E\left[x_{0}\right]\left[2-E\left[x_{0}\right]\right]}{P_{2,0}}\right] ; E_{0 \pi}=\lambda_{0}^{2}\left(1-\pi_{0}\right)^{2}$

$E_{1 i}=\left[\frac{E\left[x_{i}\right]^{2} \lambda_{i}^{2}}{2\left(1+\alpha_{1, i}\right) P_{2, i}}\right] ; E_{2 i}=\left[\frac{1}{\left(1+\alpha_{1, i}\right) P_{1, i}}+\frac{E\left[x_{i}\right]}{\left(1+\alpha_{1, i}\right) P_{2, i}}\right]$

$E_{3 i}=\left[\frac{1}{\lambda_{i}}-\frac{1}{\left(1+\alpha_{1, i}\right) P_{1, i}}-\frac{E\left[x_{i}\right]^{2}}{\left(1+\alpha_{1, i}\right) P_{2, i}}\right]$

Substitute Eqs. (A-2) to (A-4) in Eq. (A-1), we derive $E\left[T C U\left(T_{z}\right)\right]$ as follows:

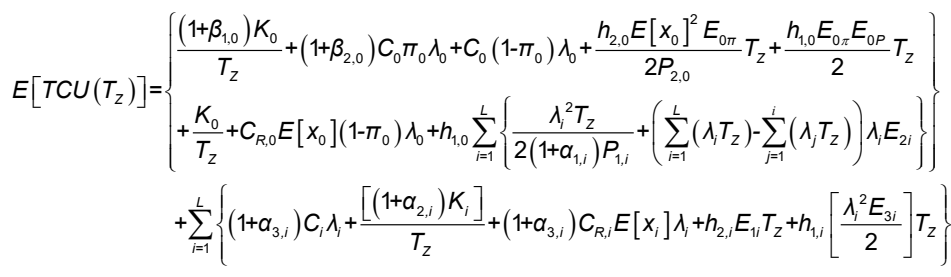

\section{APPENDIX - B}

Table B-1: The variables' values assumed of a single-stage scheme for the same problem

\begin{tabular}{|c|c|c|c|c|c|c|c|c|c|c|}
\hline Product $\mathrm{i}$ & $\mathrm{C}_{\mathrm{R}, \mathrm{i}}$ & $\mathrm{h}_{1, \mathrm{i}}$ & $\mathrm{C}_{\mathrm{i}}$ & $\mathrm{i}$ & $\mathrm{xi}$ & $\mathrm{P}_{1, \mathrm{i}}$ & $\mathrm{K}_{\mathrm{i}}$ & $\mathrm{h}_{2, \mathrm{i}}$ & $\mathrm{P}_{2, \mathrm{i}}$ & $\lambda_{\mathrm{i}}$ \\
\hline 1 & $\$ 50$ & $\$ 16$ & $\$ 80$ & 0.2 & $5 \%$ & 58000 & $\$ 17000$ & $\$ 16$ & 46400 & 3000 \\
\hline 2 & $\$ 55$ & $\$ 18$ & $\$ 90$ & 0.2 & $10 \%$ & 59000 & $\$ 17500$ & $\$ 18$ & 47200 & 3200 \\
\hline 3 & $\$ 60$ & $\$ 20$ & $\$ 100$ & 0.2 & $15 \%$ & 60000 & $\$ 18000$ & $\$ 20$ & 48000 & 3400 \\
\hline 4 & $\$ 65$ & $\$ 22$ & $\$ 110$ & 0.2 & $20 \%$ & 61000 & $\$ 18500$ & $\$ 22$ & 48800 & 3600 \\
\hline 5 & $\$ 70$ & $\$ 24$ & $\$ 120$ & 0.2 & $25 \%$ & 62000 & $\$ 19000$ & $\$ 24$ & 49600 & 3800 \\
\hline
\end{tabular}


APPENDIX - C

Table C-1: The effect of differences in outsourcing factor $\pi_{0}$ on diverse system parameters

\begin{tabular}{|c|c|c|c|c|c|c|c|c|c|c|c|c|c|}
\hline$\pi_{0}$ & $\begin{array}{c}E\left[T C U\left(T_{z}^{*}\right)\right] \\
(A)\end{array}$ & $\begin{array}{c}(\mathrm{A}) \text { in- } \\
\text { crease } \\
\%\end{array}$ & $\mathrm{~T}_{\mathrm{z}}^{*}$ & $\mathrm{t}_{1,0}(\mathrm{~B})$ & $t_{2,0}(C)$ & $\begin{array}{c}t_{0}{ }^{*} \\
(B)+(C)\end{array}$ & $\begin{array}{c}\mathrm{t}_{0}{ }^{*} \\
\text { decline } \\
\%\end{array}$ & $\begin{array}{l}\text { Utili- } \\
\text { zation } \\
\text { (D) }\end{array}$ & $\begin{array}{c}\text { (D) } \\
\text { Decline } \\
\%\end{array}$ & $\begin{array}{c}\text { Common } \\
\text { parts' } \\
\text { Rework- } \\
\text { ing cost } \\
\text { (E) }\end{array}$ & $\begin{array}{c}(\mathrm{E}) / \\
(\mathrm{A}) \%\end{array}$ & $\begin{array}{l}\text { Extra } \\
\text { cost due } \\
\text { to out- } \\
\text { sourcing } \\
\text { (F) }\end{array}$ & $\begin{array}{c}(\mathrm{F}) /(\mathrm{A}) \\
\%\end{array}$ \\
\hline 0.00 & & - & 5723 & & & & - & 56 & - & $\$ 5,314$ & $0.24 \%$ & $\$ 0$ & $0.00 \%$ \\
\hline 0.05 & & $76 \%$ & 5857 & . 0788 & 0.0012 & 0.0800 & $-2.9 \%$ & 0.2384 & $-2.9 \%$ & & $0.22 \%$ & $\$ 51,954$ & \\
\hline 10 & $\$ 2,282,364$ & $33 \%$ & 5872 & 0749 & 0012 & 0761 & $-7.6 \%$ & 0.2312 & $-5.9 \%$ & 782 & $0.21 \%$ & & $36 \%$ \\
\hline 0.15 & $\$ 2,295,187$ & $1.90 \%$ & 0.5885 & 0.0709 & 0.0011 & 0.0720 & $-12.6 \%$ & 0.2240 & $-8.8 \%$ & $\$ 4,516$ & $0.20 \%$ & $\$ 147,133$ & $6.41 \%$ \\
\hline 0.20 & & $47 \%$ & 0.5899 & .0669 & & 0.0679 & $-17.6 \%$ & 0.2168 & $-11.7 \%$ & & $0.18 \%$ & & \\
\hline 0.25 & $2,320,919$ & $3.04 \%$ & 0.5911 & 0.0628 & 0.0010 & 0.0638 & $-22.6 \%$ & 0.2096 & $-14.7 \%$ & $\$ 3,985$ & $0.17 \%$ & $\$ 242,314$ & 10.4 \\
\hline 0.30 & $2,333,827$ & $3.62 \%$ & 0.5923 & 0.0587 & 0.0009 & 0.0596 & $-27.7 \%$ & 0.2024 & $-17.6 \%$ & $\$ 3,719$ & $0.16 \%$ & $\$ 289,905$ & $12.42 \%$ \\
\hline 0.35 & & $19 \%$ & 5934 & & & & $-32.6 \%$ & 52 & $-20.5 \%$ & & $5 \%$ & & \\
\hline 0.40 & $\$ 2,359,729$ & $4.77 \%$ & 0.5944 & 0.0505 & 0.0008 & 0.0513 & $-37.7 \%$ & 0.1880 & $-23.5 \%$ & 188 & $0.14 \%$ & 5,090 & $16.32 \%$ \\
\hline 0.45 & $2,372,724$ & $5.34 \%$ & 0.5954 & 0.0464 & 0.0007 & 0.0471 & $-42.8 \%$ & 0.1808 & $-26.4 \%$ & $\$ 2,922$ & $0.12 \%$ & $\$ 432,683$ & $18.24 \%$ \\
\hline 0.50 & & $92 \%$ & 5963 & 0.0422 & & .0429 & $-47.9 \%$ & 736 & $-29.3 \%$ & 657 & $11 \%$ &, 277 & \\
\hline 0.55 & & $6.50 \%$ & 0.5970 & & 0.0 & & $-53.0 \%$ & 0.1664 & $-32.2 \%$ & 391 & $0 \%$ & 871 & \\
\hline 0.60 & $\$ 2,411,882$ & $7.08 \%$ & 0.5978 & 0.0339 & 0.0005 & 0.0344 & $-58.3 \%$ & 0.1592 & $-35.2 \%$ & $\$ 2,125$ & $0.09 \%$ & $\$ 575,466$ & $23.86 \%$ \\
\hline 0.65 & & $7.66 \%$ & 0.5984 & 0.0297 & 0.0005 & 0.0302 & $-63.3 \%$ & 0.1520 & $-38.1 \%$ & $\$ 1,860$ & $0.08 \%$ & $\$ 623,061$ & $25.69 \%$ \\
\hline 0.70 & & $8.25 \%$ & 0.5989 & 0.0255 & 0.0004 & 0.0259 & $-68.6 \%$ & 0.1449 & $-41.0 \%$ & 594 & $0.07 \%$ & $\$ 670,658$ & $27.51 \%$ \\
\hline 0.75 & $\$ 2,451,306$ & $8.83 \%$ & 0.5994 & 0.0212 & 0.0003 & 0.0215 & $-73.9 \%$ & 0.1377 & $-43.9 \%$ & $\$ 1,328$ & $0.05 \%$ & $\$ 718,254$ & $29.30 \%$ \\
\hline 0.80 & $\$ 2,464,506$ & $9.42 \%$ & 0.5998 & 0.0170 & 0.0003 & 0.0173 & $-79.0 \%$ & 0.1305 & $-46.9 \%$ & $\$ 1,063$ & $0.04 \%$ & $\$ 765,852$ & $31.08 \%$ \\
\hline 0.85 & $\$ 2,477,736$ & $10.00 \%$ & 0.6001 & 0.0128 & 0.0002 & 0.0130 & $-84.2 \%$ & 0.1233 & $-49.8 \%$ & $\$ 797$ & $0.03 \%$ & $\$ 813,449$ & $32.83 \%$ \\
\hline 0.90 & $\$ 2,490,996$ & $10.59 \%$ & 0.6003 & 0.0085 & 0.0001 & 0.0086 & $-89.6 \%$ & 0.1161 & $-52.7 \%$ & $\$ 531$ & $0.02 \%$ & $\$ 861,048$ & $34.57 \%$ \\
\hline 0.95 & $\$ 2,504,286$ & $11.18 \%$ & 0.6004 & 0.0043 & 0.0001 & 0.0044 & $-94.7 \%$ & 0.1089 & $-55.7 \%$ & $\$ 266$ & $0.01 \%$ & $\$ 908,647$ & $36.28 \%$ \\
\hline 1.00 & $\$ 2,502,939$ & $11.12 \%$ & 0.5587 & 0.0000 & 0.0000 & 0.0000 & $-100.0 \%$ & 0.1017 & $-58.6 \%$ & $\$ 0$ & $0.00 \%$ & $\$ 956,564$ & $38.22 \%$ \\
\hline
\end{tabular}


Table C-2: The effect of differences in expedited rate factor a1,0 on diverse system parameters

\begin{tabular}{|c|c|c|c|c|c|c|c|c|c|c|c|c|c|c|c|}
\hline$\alpha_{1,0}$ & $\begin{array}{c}E\left[T C U\left(T_{z}^{*}\right)\right] \\
(A)\end{array}$ & $\begin{array}{c}\text { (A) } \% \\
\text { in- } \\
\text { crease }\end{array}$ & $\mathrm{T}_{\mathrm{z}}^{*}$ & $\begin{array}{l}\text { Extra cost } \\
\text { due to } \\
\text { expedited } \\
\text { rate (B) }\end{array}$ & $\begin{array}{c}(\mathrm{B}) /(\mathrm{A}) \\
\%\end{array}$ & $\alpha_{3,0}$ & $\alpha_{2,0}$ & $\begin{array}{c}\text { Sum of } \\
t_{1, i}(C)\end{array}$ & $\begin{array}{l}\text { Sum } \\
\text { of } \\
t_{2, i}(D)\end{array}$ & $t_{1}^{*}(C)+(D)$ & $\begin{array}{c}\mathrm{t}_{1}^{*} \mathrm{de}- \\
\text { cline } \%\end{array}$ & $\begin{array}{l}\text { Utiliza- } \\
\text { tion (E) }\end{array}$ & $\begin{array}{c}\text { (E) \% } \\
\text { decline }\end{array}$ & $\begin{array}{c}\text { End } \\
\text { prod- } \\
\text { ucts' } \\
\text { rework- } \\
\text { ing } \\
\text { cost (F) }\end{array}$ & $\begin{array}{c}(\mathrm{F}) /(\mathrm{A}) \\
\%\end{array}$ \\
\hline 0.0 & $2,081,646$ & - & 0.5689 & $\$ 0$ & $0.00 \%$ & 0.00 & 0.00 & & 0.0064 & 0.0868 & - & & - & $\$ 43,834$ & $2.11 \%$ \\
\hline 0.1 & $2,137,221$ & $2.67 \%$ & 0.5742 & $\$ 55,845$ & $2.61 \%$ & 0.05 & 0.02 & 0.0737 & 0.0059 & 0.0796 & $-8.3 \%$ & 0.2250 & $-5.8 \%$ & $\$ 43,833$ & $2.05 \%$ \\
\hline 0.2 & $\$ 2,192,825$ & $5.34 \%$ & 0.5795 & $\$ 111,660$ & $5.09 \%$ & 0.10 & 0.04 & 0.0682 & 0.0054 & 0.0736 & $-15.2 \%$ & 0.2134 & $-10.7 \%$ & $\$ 43,831$ & $2.00 \%$ \\
\hline 0.3 & $, 248,448$ & $8.01 \%$ & 0.5845 & 167,447 & $7.45 \%$ & 0.15 & 0.06 & & 0.0051 & 0.0686 & $-21.0 \%$ & 0.2037 & $-14.7 \%$ & $\$ 43,830$ & $1.95 \%$ \\
\hline 0.4 & $\$ 2,304,085$ & $10.69 \%$ & 0.5895 & $\$ 223,208$ & $9.69 \%$ & 0.20 & 0.08 & 0.0595 & 0.0047 & 0.0642 & $-26.0 \%$ & 0.1953 & $-18.3 \%$ & $\$ 43,829$ & $1.90 \%$ \\
\hline 0.5 & $\$ 2,359,729$ & $13.36 \%$ & 0.5944 & $\$ 278,944$ & $11.82 \%$ & 0.25 & 0.10 & 0.0560 & 0.0045 & 0.0605 & $-30.3 \%$ & 0.1880 & $-21.3 \%$ & $\$ 43,828$ & $1.86 \%$ \\
\hline 0.6 & $\$ 2,415,379$ & $16.03 \%$ & 0.5992 & 34,656 & $13.86 \%$ & 0.30 & 0.12 & 529 & 0.0042 & 0.0571 & $-34.2 \%$ & 0.1817 & $-23.9 \%$ & $\$ 43,827$ & $1.81 \%$ \\
\hline 0.7 & $\$ 2,471,030$ & $18.71 \%$ & 0.6040 & $\$ 390,344$ & $15.80 \%$ & 0.35 & 0.14 & 0.0502 & 0.0040 & 0.0542 & $-37.6 \%$ & 0.1761 & $-26.3 \%$ & $\$ 43,826$ & $1.77 \%$ \\
\hline 0.8 & $\$ 2,526,681$ & $21.38 \%$ & 0.6087 & $\$ 446,011$ & $17.65 \%$ & 0.40 & 0.16 & 0.0478 & 0.0038 & 0.0516 & $-40.6 \%$ & 0.1711 & $-28.4 \%$ & $\$ 43,826$ & $1.73 \%$ \\
\hline 0.9 & $\$ 2,582,331$ & $24.05 \%$ & 0.6133 & $\$ 501,657$ & $19.43 \%$ & 0.45 & 0.18 & .0456 & 0.0036 & 0.0492 & $-43.3 \%$ & 0.1666 & $-30.3 \%$ & $\$ 43,825$ & $1.70 \%$ \\
\hline 1.0 & $\$ 2,637,979$ & $26.73 \%$ & 0.6179 & $\$ 557,282$ & $21.13 \%$ & 0.50 & 0.20 & 0.0436 & 0.0035 & 0.0471 & $-45.7 \%$ & 0.1626 & $-31.9 \%$ & $\$ 43,824$ & $1.66 \%$ \\
\hline 1.1 & $\$ 2,693,622$ & $29.40 \%$ & 0.6224 & $\$ 612,887$ & $22.75 \%$ & 0.55 & 0.22 & 0.0419 & 0.0033 & 0.0452 & $-47.9 \%$ & 0.1590 & $-33.4 \%$ & $\$ 43,824$ & $1.63 \%$ \\
\hline 1.2 & $\$ 2,749,261$ & $32.07 \%$ & 0.6269 & $\$ 668,473$ & $24.31 \%$ & 0.60 & 0.24 & 0.0403 & 0.0032 & 0.0435 & $-49.9 \%$ & 0.1557 & $-34.8 \%$ & $\$ 43,823$ & $1.59 \%$ \\
\hline 1.3 & $\$ 2,804,896$ & $34.74 \%$ & 0.6313 & $\$ 724,041$ & $25.81 \%$ & 0.65 & 0.26 & 0.0388 & 0.0031 & 0.0419 & $-51.7 \%$ & 0.1526 & $-36.1 \%$ & $\$ 43,823$ & $1.56 \%$ \\
\hline 1.4 & $\$ 2,860,524$ & $37.42 \%$ & 0.6357 & $\$ 779,591$ & $27.25 \%$ & 0.70 & 0.28 & 0.0374 & 0.0030 & 0.0404 & $-53.5 \%$ & 0.1499 & $-37.3 \%$ & $\$ 43,823$ & $1.53 \%$ \\
\hline 1.5 & $\$ 2,916,148$ & $40.09 \%$ & 0.6400 & $\$ 835,124$ & $28.64 \%$ & 0.75 & 0.30 & 0.0362 & 0.0029 & 0.0391 & $-55.0 \%$ & 0.1473 & $-38.3 \%$ & $\$ 43,822$ & $1.50 \%$ \\
\hline 1.6 & $\$ 2,971,765$ & $42.76 \%$ & 0.6443 & $\$ 890,640$ & $29.97 \%$ & 0.80 & 0.32 & 0.0350 & 0.0028 & 0.0378 & $-56.5 \%$ & 0.1450 & $-39.3 \%$ & $\$ 43,822$ & $1.47 \%$ \\
\hline 1.7 & $\$ 3,027,376$ & $45.43 \%$ & 0.6486 & $\$ 946,140$ & $31.25 \%$ & 0.85 & 0.34 & 0.0339 & 0.0027 & 0.0366 & $-57.8 \%$ & 0.1428 & $-40.2 \%$ & $\$ 43,822$ & $1.45 \%$ \\
\hline 1.8 & $\$ 3,082,980$ & $48.10 \%$ & 0.6529 & $\$ 1,001,624$ & $32.49 \%$ & 0.90 & 0.36 & 0.0329 & 0.0026 & 0.0355 & $-59.1 \%$ & 0.1408 & $-41.1 \%$ & $\$ 43,821$ & $1.42 \%$ \\
\hline 1.9 & $\$ 3,138,578$ & $50.77 \%$ & 0.6571 & $\$ 1,057,092$ & $33.68 \%$ & 0.95 & 0.38 & 0.0320 & 0.0026 & 0.0346 & $-60.1 \%$ & 0.1389 & $-41.9 \%$ & $\$ 43,821$ & $1.40 \%$ \\
\hline 2.0 & $\$ 3,194,169$ & $53.44 \%$ & 0.6612 & $\$ 1,112,546$ & $34.83 \%$ & 1.00 & 0.40 & 0.0311 & 0.0025 & 0.0336 & $-61.3 \%$ & 0.1372 & $-42.6 \%$ & $\$ 43,821$ & $1.37 \%$ \\
\hline
\end{tabular}

Paper submitted: 02.01.2021.

Paper accepted: 31.03.2021.

This is an open access article distributed under the CC BY 4.0 terms and conditions. 